\title{
Management, subjetividad y cultura política: el nuevo espíritu del capitalismo a veinte años de la privatización de ENTEL
}

\author{
Damián PIERBATTISTI \\ Instituto de Investigaciones "Gino Germani" \\ U.B.A. - Argentina \\ dpierbattisti@gmail.com
}

Recibido: 30-11-2010

Aceptado: 22-07-2011

\section{RESUMEN}

El proceso de privatizaciones en la Argentina no sólo constituyó uno de los ejes centrales de la llamada "Reforma del Estado", a partir de la cual comenzaría a modelarse una sociedad a imagen y semejanza de los postulados más preciados por el neoliberalismo. También involucró la imposición de un nuevo modelo de gestión de la fuerza de trabajo que se encontrará fuertemente orientado a incrementar sensiblemente la productividad laboral, subordinada a criterios individualizantes en función de los cuales se impusieron los conceptos de "empleabilidad", "modelo de competencias" "capital humano" y "cliente interno".

Estos son los rasgos que definen al nuevo espíritu del capitalismo que fuera descripto por Boltanski y Chiapello en una obra que va camino a convertirse en un tratado de las ciencias sociales del presente. En el presente artículo, y a la luz de las sugerencias que allí encontramos, nos proponemos indagar en las representaciones sociales existentes entre los trabajadores telefónicos a veinte años de producida la privatización; particularmente en lo que concierne la representación de la noción de "sindicato". Los datos que analizaremos corresponden a la lectura de nuestra base de datos que refiere a un relevamiento hecho en 2009 de 220 trabajadores en Telefónica de Argentina.

Palabras claves: neoliberalismo, representaciones sociales, privatizaciones, sindicato, management, nuevo espíritu del capitalismo, Telefónica, Argentina.

\section{Management, subjectivity and political culture: the new spirit of capitalism 20 years after the privatization of ENTEL}

\begin{abstract}
The privatization process in Argentina did not only represent one of the central axes of the so-called "State Reform", after which a society in the image and likeness of neoliberalism's most prized postulates would start to be modeled. It also involved the imposition of a new workforce management model which will be strongly oriented towards noticeably increasing labor productivity, subordinated to individualizing criteria from which stemmed the concepts of "employability", "competition model", "human capital", and "internal client".

These are the features that define the new spirit of capitalism which Boltanski and Chiapello described in a piece on its way to become a treaty of today's social sciences. In the current article, and in light of the suggestions thereby found, we set out to delve into the existing social representations among phone company workers twenty years after the privatization occurred: particularly concerning the representation of the
\end{abstract}


notion of "union". The data we will analyze corresponds to the reading of our database per a survey of 220 Telefónica de Argentina workers conducted in 2009.

Keywords: neoliberalism, social representations, privatizations, union, management, new spirit of capitalism, Telefónica, Argentina.

\section{REFERENCIA NORMALIZADA}

Pierbattisti, D. (2011). Management, subjetividad y cultura política: el nuevo espíritu del capitalismo a veinte años de la privatización de ENTEL. Cuadernos de Relaciones Laborales Vol. 30, núm. 2, p. 459-495.

SUMARIO: Introducción. 1. Marco teórico: entre Marx y tres escuelas. 2. El perfil de los "nuevos". 3. La cultura política y las representaciones sindicales. 4. El enigma de la categoría "Ninguna". 5. Reflexiones finales. 6. Referencias bibliográficas.

\section{Introducción}

La privatización de empresas públicas en la Argentina fue la forma determinante que asumió la resolución de un prolongado enfrentamiento entre las fracciones más concentradas del conglomerado capitalista local y los acreedores de la deuda externa. La suspensión de los pagos de las acreencias externas, en abril de 1988, desató la confrontación entre los actores económicos referidos por la apropiación del excedente social (Basualdo, 2006). Así, las privatizaciones suponían la forma de producir una "armonización" de los intereses de tales grupos divergentes, lo que aparece claramente plasmado en la conformación de los consorcios privados que adquirieron las empresas públicas argentinas a inicios de la década de 1990 (Azpiazu y Schorr, 2001).

Pero, al mismo tiempo, en el fenómeno de las privatizaciones se condensó uno de los ejes estructurales sobre los que se cimentó la ofensiva neoliberal en la Argentina: el decisivo fracaso de un paradigma donde lo público, y por extensión toda forma de intervención estatal en la economía, fue estigmatizado como el ámbito de la corrupción, de la improductividad y de la obsolescencia técnica.

La privatización de la Empresa Nacional de Telecomunicaciones (ENTel), que se produjera el 8 de noviembre de 1990 y que fuera adquirida por los consorcios liderados por France Télécom (zona norte del país) y Telefónica de España (zona sur), significó no sólo la primera privatización de importancia sino también aquella que marcaría una clara direccionalidad respecto de un modelo de gestión de la fuerza de trabajo (Marx, 2002) que sería implementado por las restantes privatizaciones. Dicho modelo de gestión estará fuertemente estará guiado por una idea de eficiencia y productividad en el ámbito laboral que encontrara su punto de partida en un complejo proceso de estigmatización social de los trabajadores estatales (Pierbattisti, 2005).

En tal sentido, la provocada confrontación entre "viejos" y "nuevos" trabajadores en el seno de las empresas privatizadas constituirá la base material sobre la que se impondrá una nueva filosofía empresarial. Mientras que en la primera categoría se encontraban aquellos trabajadores que habían sido alcanzados por la batería de adjetivos descalificadores que le correspondía al modelo estatal, del cual no eran 
más que una mera resultante o una simple prolongación, la segunda comprendía a aquellos que encarnaban los atributos sociales positivos que caracterizaba a la eficiencia privada en el ámbito de la economía.

La construcción de una meditada y bien delineada estigmatización social de los trabajadores estatales se subordinó a un objetivo estratégico central: reducir drásticamente el número de agentes en ambas empresas. La descalificación que acompañaba a las competencias adquiridas por estos trabajadores (Zarifian, 2001) actuaba como un factor de presión para que los ex-ENTEL se retirasen de ambas empresas por decisión propia, puesto que los acuerdos entre los sindicatos y la Administración Menem confluían en el rechazo a producir despidos masivos (Azpiazu, 2001). Por tal motivo, se diseñó una política destinada a expulsar a los trabajadores de ambas empresas que asumió el nombre de "Retiros Voluntarios". Esta constituyó una de las tácticas iniciales más importante para imponer, desde un primer momento, la proclamada "nueva cultura empresarial" que vehiculice las condiciones objetivas para lograr, por medio de innovaciones tecnológicas y la intensificación del trabajo, una productividad extraordinaria que iría a triplicar la media mundial en el sector de las telecomunicaciones (Abeles et al, 2001).

En tal sentido, las empresas licenciatarias del servicio básico telefónico se abocaron a la consecución de dos grandes objetivos estratégicos:

A) Producir un "recambio cultural" en ambas empresas mediante la incorporación de nuevos trabajadores a través de tres programas que se aplicaron simultáneamente: "Jóvenes Profesionales", "Técnicos" y "Administrativos" (o "Comerciales"). Tales programas fueron implementados desde el inicio de la privatización y al tiempo que perseguían cubrir distintas áreas centrales para la administración empresaria se proponían, también, provocar un fuerte descenso de la edad promedio del conjunto de los trabajadores e incrementar la formación académica de los mismos.

B) Destruir deliberadamente la prolongación de las "identidades heredadas" (Dubar, 1991) de los trabajadores estatales para que toda forma de poder colectivo, por más primigenia que fuese, no obstruyese la nueva comunidad de intereses individuales que se estaba construyendo.

${ }^{1}$ Tales retiros consistían en el ofrecimiento de fuertes sumas de dinero que podían llegar a triplicar el monto que correspondería por ley. Esto se aplicó fundamentalmente a los delegados y cuadros sindicales en general, los que se opusieron tenazmente a la privatización de la empresa pública. 
En este último punto reside una de las características sobresalientes del modelo managerial que se impondrá con la privatización y que ocupa hoy en día el centro del debate en la academia francesa: la individualización de los vínculos humanos y su paulatina subordinación a una grilla de inteligibilidad económica que seleccionará a los trabajadores en función de su productividad laboral. Boltanski y Chiapello (1999: 336-337) resumen adecuadamente las mutaciones culturales que se produjeron con la privatización de ENTel: "La voluntad de utilizar nuevos yacimientos de competencias en los trabajadores hasta allí sometidos al trabajo parcelario, que favorece el compromiso, conduce igualmente a incrementar el nivel de explotación. En efecto, la explotación se ve reforzada por la implementación, en el trabajo, de capacidades humanas (de relación, de disponibilidad, de flexibilidad, de implicación afectiva, de compromiso, etc.) que el taylorismo, precisamente porque trataba a los hombres como máquinas, no buscaba ni podía alcanzar. Ahora bien, este avasallamiento de las cualidades humanas pone en cuestión la separación, inscripta en el derecho, entre el trabajo y el trabajador. Lo que el trabajador compromete en la tarea depende cada vez más de capacidades genéricas o de competencias desarrolladas fuera de la empresa y, por tal razón, cada vez menos mensurable en términos de horas de trabajo; esto afecta a un número cada vez mayor de asalariados. Con los nuevos dispositivos de expresión y resolución de problemas, se les demandó a las personas movilizar más que antes su inteligencia, su sentido de la observación y su astucia en beneficio de la empresa [...] La individualización de las competencias, de las gratificaciones y de las sanciones ejerce un efecto pernicioso que tienden a hacer de cada individuo el único responsable de sus éxitos como de sus fracasos".

${ }^{2}$ Una preocupación similar a la que encontráramos a inicios de nuestra investigación ocupa el centro del debate académico francés en la actualidad, impulsado por los recientes suicidios de trabajadores en el seno de France Télécom (Baudelot y Establet, 2006; Burgi, 2007; Decèze, 2008; Dejours, 2007, 2009; Du Roy, 2009). Cabe recordar que France Télécom, empresa estatal en aquel momento, participó de la privatización de ENTel en la Argentina. Los numerosos suicidios de trabajadores ocurridos en Francia nos condujo a llevar a cabo una investigación exploratoria que se desarrolló entre los meses de septiembre y noviembre de 2010 en el seno del Laboratorio dirigido por el Prof. Christophe Dejours. Uno de los primeros resultados que arrojó el procesamiento inicial de nuestro estudio confirma que el modelo de management impuesto en France Télécom, y que suscitara una encendida reacción académica, social y política en Francia, es similar al aplicado en la Argentina hace exactos veinte años. Es precisamente a tal modelo de management al que se le adjudica una vinculación directa no solo con los suicidios sino con el incremento sensible del sufrimiento psicofísico en el trabajo. A tales efectos se sugiere consultar la página web del Observatoire du Stress et des Mobilités Forcées en France Télécom: http://www.observatoiredustressft.org/ . Es importante destacar que este sitio es el resultado de una iniciativa surgida de prestigiosos cientistas sociales y de los principales referentes sindicales que busca articular la producción de conocimiento científico, particularmente en el campo de la sociología del trabajo, con acciones sociales de carácter defensivo en virtud del embate capitalista sobre la fuerza de trabajo. 
En suma, la investigación que venimos desarrollando en los últimos años en el ámbito de las telecomunicaciones hicieron especial hincapié en la descripción del modelo managerial, particularmente en un esfuerzo por construir un marco teórico adecuado que nos permita explicar su paulatina pero creciente expansión ${ }^{3}$. A veinte años de producida la primera privatización de envergadura en la Argentina, que signaría el derrotero de la cesión de empresas públicas al campo privado, era preciso construir un instrumento científico adecuado para conocer las identidades actuales de los trabajadores telefónicos y observar qué ocurrió con aquel modelo de gestión de la fuerza de trabajo que se impuso junto a privatización. De este modo y para avanzar en la consecución de nuestro nuevo objeto de estudio, llevamos a cabo un relevamiento que consta de 220 casos y cuyo universo corresponde a los trabajadores de Telefónica de Argentina pertenecientes al Área Metropolitana de Buenos Aires (AMBA). ${ }^{4}$

En el presente trabajo nos proponemos abordar una sugerente articulación que advirtiéramos al realizar una primera interpretación de los datos derivados de tal base. Este primer ejercicio investigativo nos permitió verificar la notable incidencia que ejerce la dimensión "cultura política" (Bobbio, 1998) sobre algunos presupuestos básicos que definen el "nuevo espíritu del capitalismo", tal cual lo definen los investigadores Boltanski y Chipello en una obra que ya es un clásico de la literatura sociológica reciente.

A los fines de volver asequible el desarrollo del hilo conductor de nuestro trabajo, lo estructuramos de la siguiente manera: en primer lugar expondremos nuestro marco teórico. En segundo lugar, analizaremos las frecuencias de las dos variables que estructuraron el curso que asumió la imposición de la nueva cultura empresarial: "edad" y "nivel educativo alcanzado". Complementariamente analizaremos los porcentajes que arrojan otras dos variables que fueron conduciendo el camino investigativo que exponemos en el presente trabajo: "autodefinición laboral" y

${ }^{3}$ Podríamos incluso afirmar que, al menos en el ámbito de las telecomunicaciones y a la luz de los recientes suicidios de trabajadores telefónicos franceses, se trata de una expansión que comienza a verificarse a escala planetaria.

${ }^{4}$ Fue gracias a un subsidio obtenido de la Agencia Nacional de Promoción Científica y Tecnológica que pudimos realizar la base de datos cuyo primer análisis aquí presentamos. El Proyecto de Investigación en Ciencia y Tecnología aprobado (PICT 2006 N 1253: "Las nuevas identidades en el trabajo de las empresas privatizadas (2001-2007) nos permitió llevar a cabo un relevamiento de 220 trabajadores en Telefónica de Argentina entre enero de 2008 y marzo de 2009. Los lugares de trabajo donde se llevaron a cabo tales encuestas están constituidos por oficinas comerciales (con atención al público), administrativas (sin atención al público) y técnicas, distribuidas en la Capital Federal y la zona sur del conurbano bonaerense. El relevamiento consistió en 56 preguntas semi-estructuradas que fueron procesadas por el paquete estadístico SPSS. El autor del presente artículo fue quién tuvo a su cargo la dirección de dicho proyecto. 
"autodefinición política". En tercer lugar analizaremos las representaciones sindicales de los trabajadores telefónicos para pasar inmediatamente al análisis de una categoría en particular que atrajo fuertemente nuestra atención. Por último, en las reflexiones finales presentamos nuestras conclusiones.

\section{Marco teórico: entre Marx y tres escuelas}

"La mayoría de los desplazamientos contribuyeron a relanzar la iniciativa del capital y del management. Se trata, siempre, de obtener la colaboración de los asalariados en la realización del beneficio capitalista. Pero mientras que en el periodo precedente este resultado se buscó a partir de la presión ejercida sobre el movimiento obrero por medio de la integración colectiva y política de los trabajadores en el orden social, y por una forma del espíritu del capitalismo que liga el progreso económico y tecnológico a una pretendida justicia social, en adelante puede ser alcanzado desarrollando un proyecto de realización de sí que se liga el culto de la performance individual y de la exaltación de la movilidad a concepciones reticulares del lazo social”. (Boltanski y Chiapello, 1999: 291).

Si bien nuestras investigaciones se inscriben en la tradición científica que fundaran Marx y Engels, somos tributarios de los valiosos aportes realizados por tres grandes Escuelas que nutrieron significativamente la conformación de nuestro marco teórico: el New Public Management (Savas, 1987; Andrisani et Al., 2002, Osborne y Gaebler, 1992), los Governmentality Studies (Rose, 1999; Rose y Miller, 1992; Burchell, Gordon y Miller, 1991) y la Critical Management Studies (Alvesson y Willmott, 1992; Fernández Rodríguez, 2008).

Profundizar en los aportes que cada una de estas Escuelas realizó a la teoría social a lo largo de los últimos treinta años nos desviaría sensiblemente de nuestro objeto de estudio. Sin embargo podemos reseñar, brevemente, los principales elementos que tomamos de estas tres grandes corrientes de pensamiento para la construcción de nuestro marco teórico.

En primer lugar, el New Public Management (NPM) pone el acento en la discusión filosófica que impulsa la reforma del Estado para ciertas vertientes del neoliberalismo: "En primer lugar, la privatización es mucho más que una operación financiera o un acto de gestión, es una posición filosófica respecto a los roles que deben jugar las instituciones privadas y el Estado, y la relación entre ellos. Las principales instituciones privadas de la sociedad son el mercado, las asociaciones sin fines de lucro de todas las clases (sociedad civil) y la familia. La privatización es el acto de reducir la intervención del Estado o aumentar el papel de las instituciones privadas, en la satisfacción de las necesidades de los individuos en una sociedad determinada; significa depositar más confianza en el sector privado y menos en el público" (Savas, 2000: 115). 
Esta posición conceptualiza el isomorfismo que encontramos entre la gestión pública y los parámetros de productividad propios del campo privado en los diversos procesos privatizadores llevados a cabo no sólo en la Argentina, como pudimos reflejar en una reciente investigación (Pierbattisti, 2011). Es así como encontramos en el centro de las preocupaciones del NPM la necesidad de agilizar la gestión pública que, según esta corriente de pensamiento, se encuentra fuertemente limitada por su estructural ineficiencia: "La cuestión central de este movimiento [NPM] es la noción de supresión de las diferencias organizacionales entre los sectores públicos y privados para reducir la ineficiencia del sector público por medio de intentos focalizados en la obtención de resultados a partir del Management" (Carter, 2006: 139).

En las antípodas de esta posición encontramos a los Governmentality Studies (GS). Fuertemente imbuidos por los estudios emprendidos por el filósofo francés Michel Foucault acerca de la noción de "gobierno" (Foucault, 1982), Nikolas Rose y Peter Miller intentan pensar el gobierno como el dominio de estrategias, técnicas y procedimientos a través de los cuales las diferentes fuerzas sociales buscan implementar sus programas. Estos autores llaman al conjunto de tales mecanismos heterogéneos tecnologías de gobierno (Rose y Miller, 1991: 183).

Para esta corriente teórica, la noción de gobierno remite al hecho de administrar la heterogeneidad social a partir de la implementación de un arsenal tecnológico que pueda recubrir la totalidad del tejido social. En tal sentido, son los aportes teóricos producidos por estos estudios los que nos permiten formular que el neoliberalismo es la forma particular que asume una cierta tecnología de gobierno cuyo desarrollo y desenvolvimiento atravesó la historia reciente del capitalismo. Así, "uno de los mecanismos centrales del neoliberalismo consiste en la proliferación de estrategias para crear y sostener un mercado y para reorganizar las formas de los intercambios económicos sobre las bases de los intercambios contractuales. Los programas de privatizaciones pueden ser vistos como los rasgos más visibles de tales estrategias y como los más alineados con los ideales políticos del mercado versus el Estado" (Rose y Miller, 1991: 199).

Por último, llegamos a los Critical Management Studies (CMS). Esta escuela se caracteriza por sus agudas críticas a "los conceptos de excelencia, reingeniería o competencias, para hablar de feminismo, de represión al deseo y de resistencia a la dirección. Se critica duramente a los famosos gurús de la gestión como Tom Peters, Peter Drucker o Michael Champy para reivindicar el trabajo de Michel Foucault, Jacques Derrida o incluso nada menos que Toni Negri y esto lo hacen en un curso de formación de ejecutivos" (Fernández Rodríguez, 2008: 2).

Pero ya se trate de acompañar la irrupción de criterios de gestión empresarial en el ámbito de la administración pública (NPM), de reflexionar en torno a las nuevas tecnologías de poder que despliega el neoliberalismo en su expansión planetaria (GS) o de cuestionar fuertemente el modelo managerial que caracteriza a las grandes empresas capitalistas actuales (CMS), estas tres Escuelas abordan objetos precisos de estudio que requieren ser articulados. En este sentido, la obra de Boltanski y Chiapello (1999) permite integrar estos tres aportes. 
Enfocando el análisis hacia la cuestión managerial, que es el tema de nuestra investigación, en esta obra se advierte que: "uno de los elementos característicos de la literatura de management, cuando se la lee para extraer los ideales-tipos del espíritu del capitalismo en las dos épocas, es la preocupación permanente de movilización y motivación del personal, sobre todo de los mandos, "«¿Cómo dar un sentido al trabajo en empresa?»” (Boltanki y Chiapello, 1999: 100).

La literatura de los años '60, relevada por estos autores, tiene como eje la profunda insatisfacción de los mandos medios y altos, tributaria de un fenómeno que tendía a desvirtuar el carácter capitalista de las organizaciones empresariales: su burocracia y el estricto ordenamiento jerárquico. En efecto, ambas dimensiones se asociaban peligrosamente con la caracterización organizativa que correspondía a los países socialistas del bloque soviético donde las mismas se articulaban para desalentar toda forma de iniciativa individual que pudiese volver más eficiente a la empresa.

No es un dato menor que Boltanski y Chiapello señalasen que la forma de hacer frente a este problema, provendrían de la articulación de tres tácticas diferentes: "descentralización", "meritocracia" y "dirección por objetivos". De la confluencia virtuosa de estos tres conceptos resultaría la construcción de una novedosa "autonomía", que, aunque cernida a la consecución de objetivos específicos, beneficiaría a los mandos y tendería a contrarrestar su posible desmotivación. No obstante, estas innovaciones organizativas no ponen en crisis la lógica del "mundo doméstico" que continuaba rigiendo los modelos organizativos de aquel entonces, fuertemente anclados en la antigüedad en la empresa como un criterio distintivo de fidelidad a la misma. Así, la garantía del puesto de trabajo jugaba un rol central para las configuraciones descriptas en la literatura managerial de los años '60. No obstante, treinta años más tarde, la irrupción del concepto de "empleabilidad" pondría fin al modelo de "empleo de por vida" que caracterizaba a las organizaciones de la posguerra.

Es este el concepto el que abrirá las puertas al diseño de un nuevo modelo organizacional que establece nuevos criterios de legitimidad para mantener el puesto de trabajo, particularmente en las grandes organizaciones. Es así como "la empleabilidad designa la capacidad de las que las personas deben estar dotadas para que se las convoque a diversos proyectos. El paso de un proyecto a otro es la ocasión de incrementar la empleabilidad. Este es el capital personal que cada uno debe administrar y que está constituido por la sumo de las competencias movilizables" (Bolta, 144-145).

Nuestra definición del concepto de empleabilidad difiere sustancialmente de la que ofrecen Boltanski y Chiapello, pero discutiremos este punto en las conclusiones de nuestro trabajo. No obstante, también la cuestión de la empleabilidad está presente en la literatura del management de los años ' 90 , referida a la centralidad que asumirán la imposición de un modelo de competencias destinado a decodificar la empleabilidad de cada trabajador. La creciente individualización de los vínculos humanos al interior del espacio de trabajo que persigue el nuevo modelo managerial, y del que da cuenta la literatura del período, se apoya en la paulatina expansión de la teoría del capital humano (Schultz, 1971; Becker, 1994). Uno de los ejes más 
dinámicos de esta teoría descansa sobre una creciente responsabilización de los trabajadores sobre su propio destino en el mercado de trabajo a partir de administrar, concientemente, sus capacidades y competencias como si se tratase de un "empresario de sí mismo" (Foucault, 2004). En tal sentido, los innumerables cursos de formación destinados a "reconvertir" a la fuerza de trabajo existente en TDA al momento de la privatización dan cuenta de la importancia que asumían los criterios individualizados de selección de trabajadores en el contexto descripto de "recambio cultural". Sin duda alguna en esta sensible mutación epistemológica encontramos el origen de la ruptura con el modelo managerial anterior: la noción de empleo de por vida es reemplazada por la de empleabilidad, dando paso a la centralidad que tendrá para todos los miembros de la organización, y no solo los cuadros medios y jerárquicos, el pleno desarrollo de los proyectos individuales y de las potencialidades creativas de cada quien. La exigencia irrestricta de productividad laboral, que caracteriza al nuevo management impuesto en los años ' 90 , produce dos efectos ineludibles: por un lado determina la inserción efectiva de cada persona en el mercado de trabajo y por otro lado democratiza los criterios a los que debe ajustarse la fuerza de trabajo en su conjunto (perimida la legitimidad que se le otorgaba en el paradigma anterior al empleo garantizado de por vida). El creciente aumento del desempleo, los procesos de flexibilización de las leyes destinadas a regular el consumo productivo de los cuerpos y la creciente desindicalización que acompaña a los procesos privatizadores, constituyen las garantías materiales de las que se vale el avance capitalista sobre la fuerza de trabajo; al tiempo que condicionan notablemente el margen de maniobra de los sindicatos.

Sin embargo, consideramos que de la descripción aguda y minuciosa de los contenidos que distingue a los modelos manageriales que confrontamos en nuestra investigación no se desprende en absoluto una consecuencia lógica de su posible éxito como de su fracaso. Fue por tal motivo que nos decidimos a llevar a cabo un relevamiento que nos refleje el estado actual de las identidades laborales de cierta fracción de los trabajadores telefónicos argentinos, aquellos que ocuparon el centro de nuestras investigaciones precedentes, y poder así constatar el destino final del modelo de gestión que se impuso con la privatización de ENTel.

Para ello partimos de una sugerencia inicial: "En tanto que ideología dominante, el espíritu del capitalismo tiene, en principio, la capacidad de penetrar el conjunto de las representaciones mentales propias de una época dada, de infiltrar los discursos políticos y sindicales, de proveer representaciones legítimas y esquemas de pensamiento a los periodistas e investigadores, aunque su es, a la vez, difusa y general" (Boltanki y Chiapello, 1999: 94).

En esto consistían, precisamente, los "Modelos mentales" que TDA exhortaba a modificar para volver más eficiente a la organización. Tales modelos mentales referían a "imágenes internas profundas sobre el funcionamiento del mundo, imágenes que nos limitan a modos de pensar y de actuar.". Modificar estos viejos « modelos mentales» es de una importancia extrema ya que "éstos "no determinan solamente el modo de interpretación del mundo, sino también el modo de acción. El problema de los modelos mentales no en que sean atinados o erróneos. Por defini- 
ción, todos los modelos mentales son simplificaciones de la realidad". Uno de los rasgos salientes del nuevo management refiere a que provee los elementos para que cada trabajador detecte y reconozca, por medio de la formación y la capacitación, sus propios modelos mentales. Lejos de constituir un ámbito de encierro, TDA impulsaba a "pensar los modelos mentales como un conjunto de aptitudes que se pueden desarrollar" 5 .

Los "modelos mentales" aludidos designaban un conjunto de representaciones cuyas "rigideces" impedían, siempre desde la perspectiva empresarial, enfrentar los procesos de cambio organizacional que exigían la disolución de los antiguos paradigmas. Como bien refleja la literatura managerial de los años '60 abordada por Boltanski y Chiapello, la cultura laboral que caracterizaba a la gestión de las empresas públicas carecía de los tres elementos que le otorgaran su sesgo distintivo al "pensamiento creativo" demandado por las empresas privatizadas: "Fluidez" ("Se evalúa la cantidad de ideas que surgen ante un problema, asociadas a un mismo origen en un espacio de tiempo limitado"); "Flexibilidad" ("Se evalúa la capacidad de experimentar enfoques totalmente distintos de un mismo problema, tendiendo a la generación de soluciones no tradicionales") y "Originalidad" ("Se trata de una respuesta totalmente innovadora ante un problema en un contexto dado") ${ }^{6}$.

Tales conceptos fueron estructurantes para redefinir la cultura laboral heredada por Telefónica de Argentina. Pero al mismo tiempo reflejan la existencia de una necesaria contrapartida que no pocas veces se ignora y que nos remite a diversas instancias de examen a las que serán sometidos los trabajadores para verificar si, realmente, cumplen con tales requisitos. De allí que remarcáramos con especial énfasis que el norte de la nueva cultura organizacional refiera al incremento sensible, permanente y constante de la productividad laboral que asumirá formas cada vez más se individualizadas.

Por otra parte, es importante remarcar que de un análisis profundo y minucioso de los cursos de capacitación se desprende una preocupación que involucra la direccionalidad real que asume la expansión de la formación social capitalista a nivel mundial. En definitiva éste es el factor por excelencia que inspira la necesidad de readecuarse a los cambios: "En los últimos tiempos, las empresas han comenzado a comprender que, incluso sus mandos inferiores, sus empleados profesionales y sus técnicos necesitan adoptar el papel de líderes en sus respectivos campos de acción. Por ejemplo: el alto grado de competitividad exige que un número cada vez mayor de jóvenes profesionales coordinen grupos formados por mandos de producción, de comercialización y de ventas en el desarrollo de nuevos productos. Esta exigencia hace que, a su vez, dichos profesionales deban poseer el atributo del

${ }^{5}$ Telefónica de Argentina - Dirección de Recursos Humanos - Servicio de Formación: Creatividad y cambio organizacional. Mayo de 1991. pág. 7. Cursiva y negrita pertenecen al original.

${ }^{6}$ Op. cit., págs.. 20-21. Cursiva y negrita pertenecen al original. 
liderazgo. En tiempos de guerra, tanto el gobierno como en las fuerzas armadas, el liderazgo cobra mayor importancia. Lo mismo ocurre con el liderazgo en los negocios cuando estalla una guerra en las esferas económicas. Es por esto que cuantas más personas se encuentren preparadas, mejor"?

La guerra económica se encuentra impulsada por la competencia capitalista en un contexto de singular y profunda desregulación y apertura de diferentes mercados nacionales. Sin tomar esta perspectiva de análisis como un punto de partida sustancial, difícilmente puedan evaluarse correctamente no sólo la profundidad de los cambios suscitados con la privatización de ENTel sino también cuáles son las razones que subyacen al diseño estratégico de la nueva cultura empresarial y de la filosofía que la inspira.

\section{El perfil de los "nuevos"}

Al momento de la privatización, el conjunto de los trabajadores de ENTel se repartió de manera equitativa entre "Telefónica de Argentina" (TDA) y "Telecom Argentina" (TA), correspondiendo para cada empresa poco más de veinte mil personas. Ambas compañías juzgaron que la cantidad de trabajadores era excesiva e implementaron dos políticas que, aplicadas simultáneamente, provocaron el ansiado "recambio cultural", tal cual describiéramos en la introducción del presente trabajo: "Retiros Voluntarios" y reclutamiento de Jóvenes Profesionales, Técnicos y Administrativos.

No sólo eran muchos sino que, además, eran muy viejos. Sin embargo, la consecución exitosa del "recambio cultural" será posible por las innovaciones tecnológicas producidas inmediatamente después de la privatización. Es en el tránsito de las centrales electromecánicas a las centrales digitales, que rápidamente permitió digitalizar el conjunto de la red telefónica del país, y de las máquinas de escribir a la informatización de las labores administrativas, donde se volvió observable la eficacia política que perseguía el proceso de estigmatización social del que fueran objeto los ex-ENTel. En efecto, esta táctica descansaba sobre fondo de desalentar la permanencia de estos trabajadores en la empresa a partir de verificar, por sí mismos, que la profundidad de los cambios impulsados con la privatización, particularmente en materia tecnológica, no los incluía. Los "nuevos" eran la encarnación misma de una identidad laboral que daba cuenta no sólo del nuevo mundo empresarial en ciernes sino también de la obsolescencia técnica que ostentaba el paradigma bajo el cual se habían formado. La irrupción de las computadoras personales en el ámbito de trabajo no hacía más que reflejar la cruda objetividad del estigma atribuido.

${ }^{7}$ Op. cit. Pág. 27. 
Es así, entonces, que la secuencia "estigmatización social", "innovaciones tecnológicas" y "retiros voluntarios" funcionó como un aceitado dispositivo destinado a crear las condiciones necesarias para producir un extendido "recambio cultural" en TDA.

El gráfico $n^{\circ} 1$ pone de relieve el éxito esta política:

\begin{tabular}{|c|c|c|c|c|c|}
\hline \multicolumn{6}{|c|}{$\begin{array}{c}\text { GRÁFICO No } 1 \\
\text { INDICES DE PRODUCTIVIDAD DE TELEFONICA Y TELECOM, 1990-1999 }\end{array}$} \\
\hline PERIODO & $\begin{array}{l}\text { LINEAS EN } \\
\text { SERVICIO }\end{array}$ & $\begin{array}{l}\text { PERSONAL } \\
\text { OCUPADO }\end{array}$ & $\begin{array}{c}\text { LINEAS EN } \\
\text { SERVICIO } \\
\text { POR } \\
\text { PERSONAL } \\
\text { OCUPADO }\end{array}$ & $\begin{array}{c}\text { LINEAS EN } \\
\text { SERVICIO } \\
\text { CADA } 100 \\
\text { HABITANTES }\end{array}$ & $\begin{array}{c}\text { GRADO } \\
\text { DE } \\
\text { DIGITALI } \\
\text { ZACION } \\
\text { DE LA } \\
\text { RED } \\
\end{array}$ \\
\hline \multicolumn{6}{|c|}{ TELEFONICA } \\
\hline Nov.90 & 1.695 .504 & 21.770 & 77,9 & 12,0 & $14,6 \%$ \\
\hline Sept. 99 & 3.934 .178 & 10.186 & 386,2 & 22,9 & $100,0 \%$ \\
\hline Variación & $132,0 \%$ & $-53,2 \%$ & $395,8 \%$ & $90,8 \%$ & \\
\hline \multicolumn{6}{|c|}{ TELECOM } \\
\hline Nov.90 & 1.401 .969 & 19002 & 73,8 & 11,2 & $11,5 \%$ \\
\hline Sept.99 & 3.422 .596 & 9275 & 369 & 19,1 & $100 \%$ \\
\hline Variación & $144,1 \%$ & $-51,2 \%$ & $400 \%$ & $70,5 \%$ & \\
\hline \multicolumn{6}{|c|}{ TELEFONICA + TELECOM } \\
\hline Nov.90 & 3.097 .473 & 40722 & 76,0 & 11,6 & $13,1 \%$ \\
\hline Sept.99 & 7.356 .774 & 19461 & 378,0 & 21 & $100,0 \%$ \\
\hline Variación & $137,5 \%$ & $-52,3$ & $397,4 \%$ & $81 \%$ & \\
\hline
\end{tabular}

Fuente: Área de Economía y Tecnología de la FLACSO, 2001.

Como se observa en este gráfico, durante los diez primeros años que transcurrieron desde el inicio del proceso privatizador, el número inicial de trabajadores se reduce a menos de la mitad; al tiempo que la digitalización de la red alcanza su 
valor absoluto. En principio podríamos afirmar que uno de los primeros objetivos estratégicos, incrementar de manera extraordinaria la productividad laboral, fue cumplido satisfactoriamente. ${ }^{8}$

No obstante, el objetivo concomitante referido a la reducción de la edad promedio de los trabajadores y al incremento de su formación académica no aparece cristalizado en el cuadro expuesto.

Según declaraciones de mandos medios del Departamento de Recursos Humanos (RR.HH.) de Telefónica de Argentina, la edad promedio de los trabajadores al momento de la privatización era de unos 47 años aproximadamente (Pierbattisti, 2005). En el gráfico que sigue exponemos las frecuencias de la variable edad para conocer si a lo largo de los veinte años transcurridos TDA logró producir el drástico descenso en el promedio de edad de los trabajadores tal cual se lo había propuesto originalmente 9 . Para facilitar la lectura del gráfico distribuimos las frecuencias en cuatro grandes franjas etarias:

${ }^{8}$ La fórmula para medir la productividad en este sector, la expresa el cociente que resulta de las líneas telefónicas en servicio por cantidad de empleados. No cuesta mucho imaginar el aumento de la productividad que lograron ambas empresas a partir de articular la digitalización de las redes y la política de despidos masivos que llevaron a cabo, particularmente, durante los primeros años posteriores a la privatización de ENTEL. El fuerte aumento de líneas telefónicas instaladas, la drástica supresión de puestos de trabajo y la intensificación del consumo productivo de la fuerza de trabajo incrementó exponencialmente la productividad laboral en un breve lapso.

${ }^{9}$ Lamentablemente, y por razones que escapan a nuestra voluntad, no hemos tenido ocasión de ponderar los datos existentes en nuestra base. Tal deficiencia no escapa a las enormes dificultades que debimos sortear para llevar a cabo el relevamiento del cual aquella resulta, particularmente en lo que concierne las múltiples trabas que nos fueron impuestas para acceder a los diversos ámbitos de trabajo. La ponderación de nuestra base hubiese sido posible a partir de obtener los datos precisos del conjunto de los trabajadores que componen el universo de la base en cuestión que sólo el Departamento de RR.HH. estaba en condiciones de brindarnos, una auténtica quimera. 


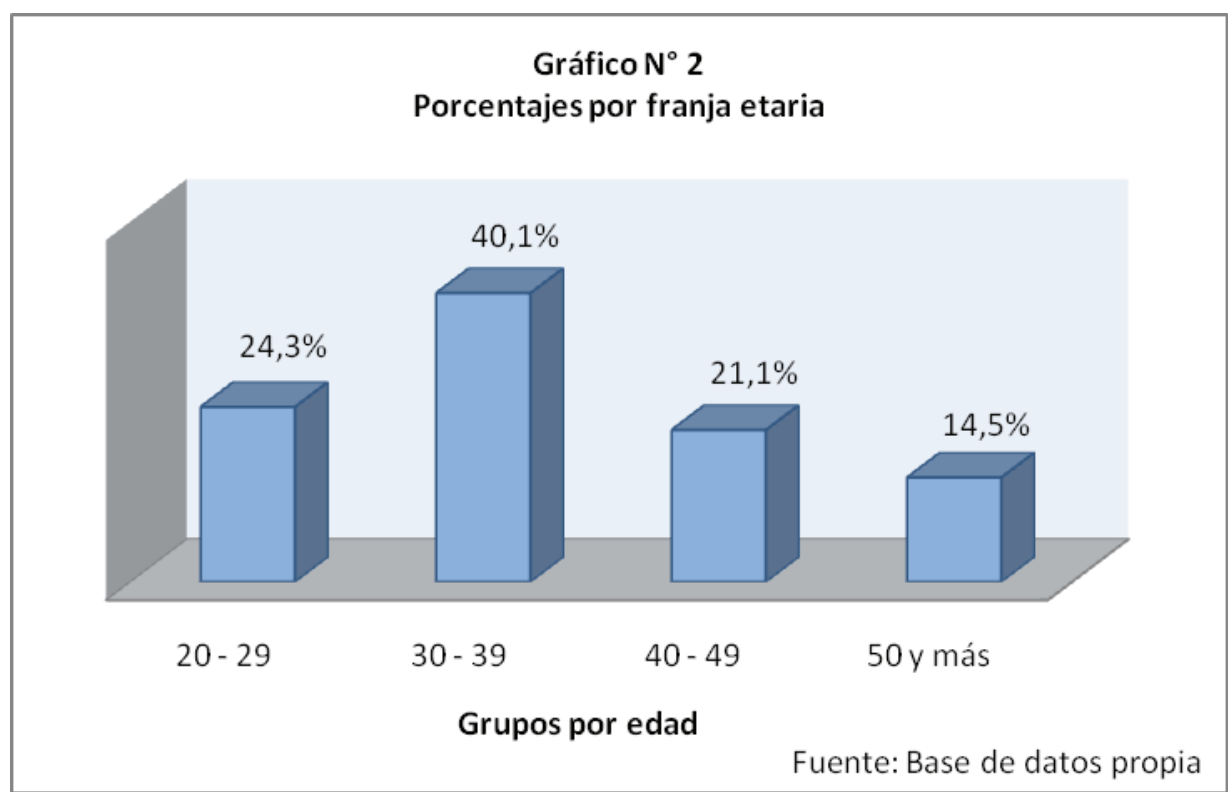

Este gráfico nos indica que las dos primeras franjas etarias a partir de las cuales distribuimos la variable "edad" concentra el $64,4 \%$ de la población relevada. En otras palabras, más de 6 de cada diez trabajadores de TDA no tiene más de 39 años mientras que la media se ubica alrededor de los 37 años. Es decir que el promedio de edad se redujo un $21,3 \%$ respecto del existente al momento de la privatización de ENTel, con lo cual podemos concluir que este objetivo también fue alcanzado holgadamente.

La restante variable que nos permitirá poner en correspondencia otro objetivo político que se trazó TDA al momento de la privatización, refiere a la variable "nivel educativo". El gráfico no 3 es elocuente al respecto: 


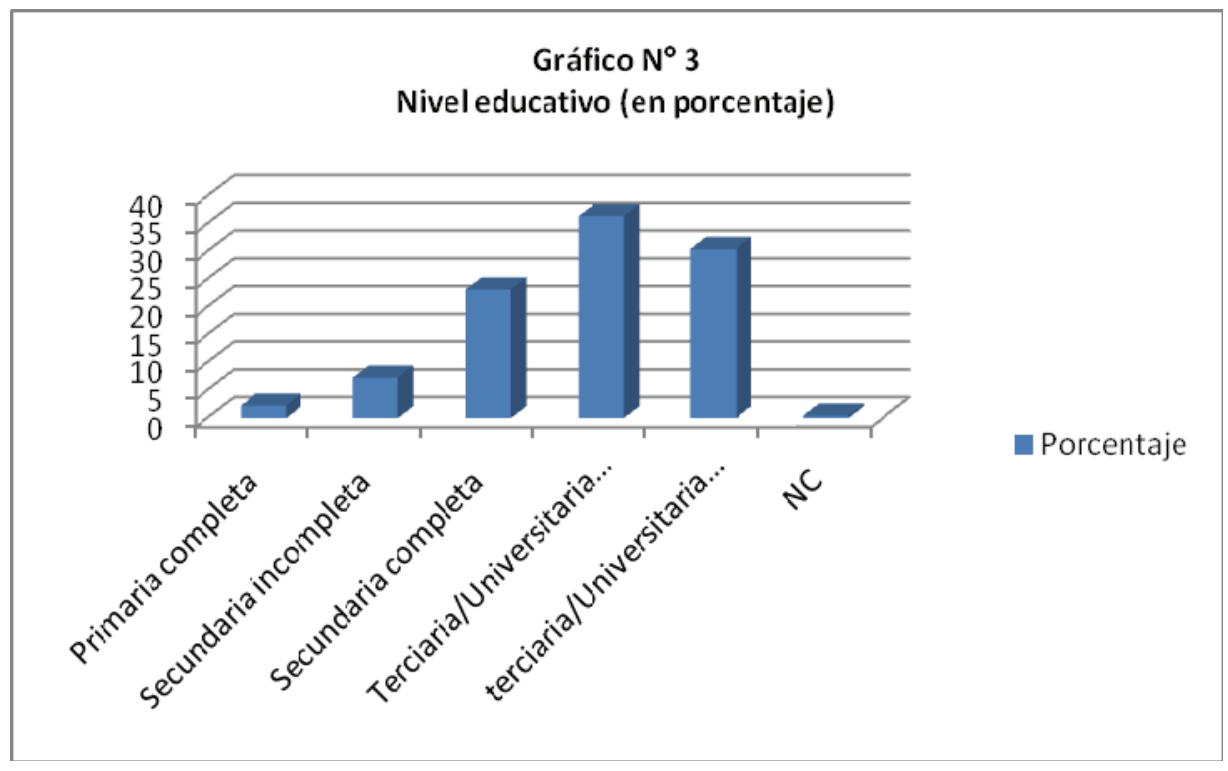

El gráfico $n^{\circ} 3$ nos ofrece la posibilidad de dividir la población en tres tercios que se distribuyen de manera homogénea: un primer tercio constituido por el $32,7 \%$ de trabajadores que alcanzaron hasta la secundaria completa, un 36,3\% de trabajadores que no completaron sus estudios universitarios mientras que un $30,5 \%$ sí lo hizo (sólo un entrevistado no respondió esta pregunta lo que constituye un marginal $0,5 \%$ de los casos).

Los datos expuestos demuestran una clara tendencia respecto de los objetivos trazados por TDA al momento de haber asumido la administración de la que fuera la empresa pública de telecomunicaciones. Esta tendencia se ve reforzada porque nuestra base refiere al conjunto de trabajadores de una misma empresa y a un proceso social cuyas características sobresalientes estudiamos en profundidad. En tal sentido y de manera análoga a las variables precedentes, estamos en condiciones de afirmar que el objetivo de aumentar sensiblemente el nivel educativo de los trabajadores telefónicos fue indiscutiblemente exitoso.

No obstante, si continuamos avanzando en la lectura de nuestra base de datos en función de los objetivos que se trazó TDA originalmente, advertiremos que la consecución de tales logros dista de trasladarse mecánicamente a la dimensión subjetiva, espacio donde se expresaría la nueva y deseada cultura empresarial.

Para conocer esta dimensión, indagamos en torno a la "autodefinición profesional" de los trabajadores. En esta variable la intención original de la empresa por imponer las personificaciones asociadas al nuevo modelo managerial, cuya socialización se produjo por medio de los referidos cursos de capacitación, distan de constituir un logro empresario. 
Observemos el gráfico $n^{\circ} 4$ :

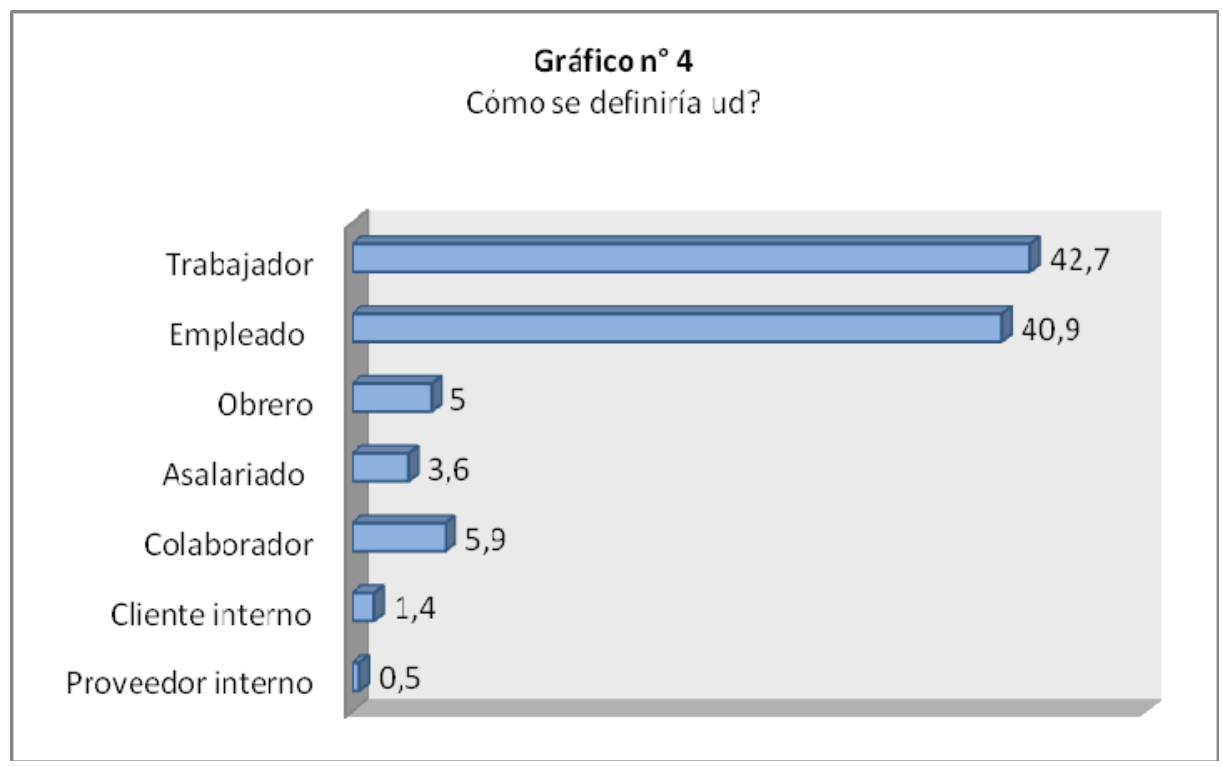

Las tres últimas categorías son la expresión acabada de las nuevas identidades laborales que impuso TDA, inimaginables antes de la privatización. Sin lugar a dudas, aquellas refieren a los minuciosos mecanismos de disolución y atomización de las identidades colectivas que, siempre desde la óptica empresarial, constituían un verdadero escollo para la imposición de la nueva cultura organizacional.

Este no es un punto que haya sido librado al azar. Ya a inicios de 1991, a pocos meses de producida la privatización, en el Cuaderno de Formación que lleva por título "Relaciones Interpersonales" la empresa se ocupa de recodificar las relaciones sociales en el interior del ámbito de trabajo procurando invisibilizar los intereses colectivos al reducir el trabajo a un intercambio de servicios entre iguales: un "cliente interno" será "estas personas o sectores que reciben trabajos hechos por tras personas $\mathrm{u}$ otros sectores de la empresa. Los clientes internos deben recibir el mismo respeto, consideración y calidad de servicio que los clientes externos". ${ }^{10}$

Podríamos profundizar esta perspectiva, pero nos alejaría de nuestro objeto de estudio. Como subrayáramos más arriba, la individualización de los vínculos humanos es una característica central no sólo del nuevo modelo managerial sino también

${ }^{10}$ Telefónica de Argentina - Dirección de Recursos Humanos - Servicio de Formación: Relaciones Interpersonales. Buenos Aires, 1991, pag. 5 
de la literatura que lo inspira y describe, como bien destacan Boltanski y Chiapello. $\mathrm{Y}$ en este sentido, es interesante observar que las frecuencias de la variable "autodefinición laboral" no estarían registrando la dimensión de la ofensiva en juego hace veinte años: las categorías "trabajador" y "empleado" reúnen el 83,6\% de la muestra, repartidos de manera casi equitativa"

En principio, esta situación nos plantea una serie de sugerencias muy fuertes ya que, es evidente, la autodefinición identitaria de los trabajadores telefónicos indicaría un fuerte rechazo a las formas semánticas que resultaran del deseado "recambio cultural". Sin embargo, un análisis más profundo de nuestra base nos lleva a relativizar esta presunta "derrota" del campo empresarial.

\section{La cultura política y las representaciones sindicales}

Uno de los principales obstáculos que encontraba TDA para imponer una cultura empresarial que se estructurara a partir del incremento permanente de la productividad laboral, era el profundo enraizamiento de la cultura sindical entre los trabajadores. Con esto procuramos englobar a los diversos gremios que nucleaban a los distintos escalafones profesionales de la empresa ${ }^{12}$. Por tal motivo, nos resulta central conocer si existe una posible correlación entre la cultura política que expresan los trabajadores y el posible vínculo existente con la dimensión sindical. Pero antes de avanzar sobre tal posible asociación, es preciso conocer previamente cómo se autodefinen políticamente los propios trabajadores. Observemos el gráfico $\mathrm{n}^{\circ} 5$ :

${ }^{11}$ Sabemos que indagar en las razones por las cuales una persona opta por definirse como "trabajador" o "empleado" constituye un desafío intelectual al que nos vemos enfrentados. Una hipótesis conducente a explicar tales diferencias en la "autodefinición laboral", que prácticamente divide a la población en mitades exactas, nos remite a sumar a la dimensión "cultura política" el carácter del trabajo en sí, ya se trate de trabajo manual o intelectual. Profundizar esta perspectiva nos aleja del objetivo que persigue el presente artículo, circunscripto a escrutar la incidencia de la dimensión "cultura política" en la representación sindical de los trabajadores telefónicos.

${ }^{12}$ Diferentes agrupamientos sindicales expresaban, nítidamente, la heterogeneidad de identidades sociales y laborales dentro de ENTEL: la Unión del Personal Jerárquico de Empresas de Telecomunicaciones (UPJET); la Federación que nucleaba a la Organización del Personal de Supervisión, Técnicos y Telefónicos Argentinos (FOPSTTA); la Federación de Obreros Empleados Telefónicos de la República Argentina (FOETRA) y el Centro de Profesionales Telefónicos (CEPETEL). 


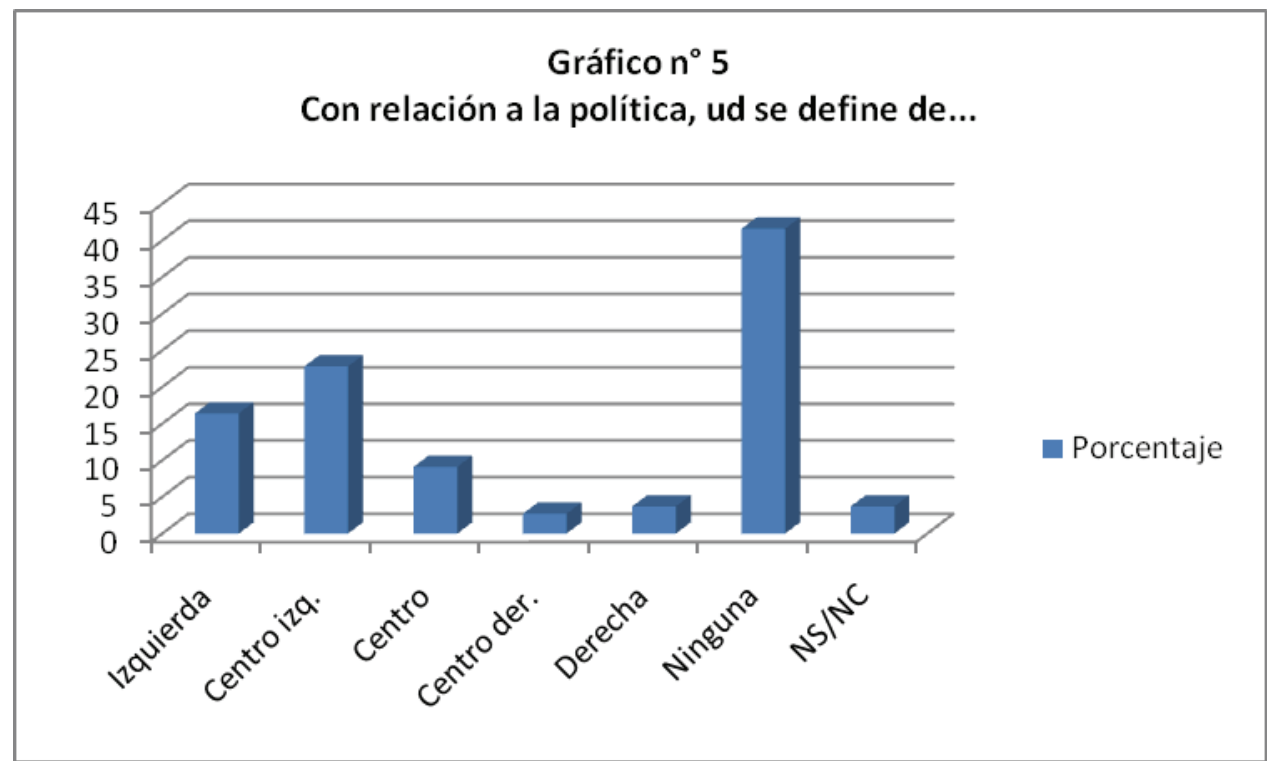

En las frecuencias de la variable "autodefinición política" encontramos que el $39,1 \%$ de los trabajadores telefónicos se encuadran en lo que, de forma laxa, podríamos llamar una "cultura política de izquierda". Tan solo un 6,6\% se define de derecha y centro derecha mientras que un $9,1 \%$ se ubica en el centro del espectro político. Sin embargo, tenemos un elevado $41,4 \%$ que no se define de ninguna manera o que, para ser más exactos, opta por la categoría "Ninguna" al momento de definirse políticamente ${ }^{13}$.

Puesto que nuestro interés está referido en escrutar la posible relación que se establece entre la cultura política de los trabajadores telefónicos y sus representaciones sindicales, es interesante señalar que la curiosa distribución de las frecuencias pertenecientes a la variable "autodefinición política", particularmente en lo que concierne a la categoría "Ninguna", incrementó nuestra inquietud inicial.

${ }^{13}$ Es central mencionar que al momento de llevar a cabo el relevamiento, la categoría "Ninguna" y "NS/NC" no eran formuladas para no inducir una respuesta anticipada, lo que marca claramente la voluntad de encuadrarse por fuera de toda definición política. 
La referencia a lo que denominaremos "mundo sindical" no es antojadiza ${ }^{14}$. Los sindicatos constituyen uno de los mayores obstáculos que enfrenta el despliegue del nuevo espíritu del capitalismo, puesto que se opone en un todo a la pretendida coexistencia pacífica de intereses individuales interdependientes entre sí que caracteriza a la cultura organizacional surgida de las privatizaciones. Los resultados que siguen a continuación procuran abrir un campo de discusión sobre la caracterización que elaboran Boltanski y Chiapello sobre las profundas transformaciones que atravesara el orden social capitalista a los largo de los últimos treinta años; que en la Argentina se impuso con singular nitidez con el proceso de privatizaciones y de Reforma del Estado de los años '90, pero que hunde sus raíces en la determinación genocida de la última dictadura militar (Basualdo, 2006).

Ahora bien, para abordar las representaciones sobre el "mundo sindical" de los trabajadores telefónicos construimos una variable para observar el grado de aproximación que los mismos "sienten" respecto de tres estamentos sindicales: "Delegados de la Comisión Interna", "Dirigentes de FOETRA" y "Dirigentes de la CGT",15.

Analicemos el Cuadro ${ }^{\circ} 1$. Para observar con mayor comodidad y nitidez la articulación de ambas dimensiones procedimos a agrupar las categorías que expresan tanto los grados de proximidad como la cultura política de los trabajadores. Los valores expresan puntos porcentuales mientras que para conocer la posible la asociación de las variables aplicamos el coeficiente de correlación "chi cuadrado" de Pearson:

${ }^{14}$ Llamamos "mundo sindical" a todos los discursos, prácticas y representaciones que conciernen al desenvolvimiento mismo de las diversas organizaciones sindicales como expresión de los intereses comunes de un determinado colectivo de trabajo asalariado. En el caso que nos ocupa, nos ceñiremos al análisis de las representaciones que sobre ese mundo expresan los trabajadores telefónicos del AMBA en la Argentina.

${ }^{15}$ En la base de datos sobre cuya información estamos trabajando contamos con otros diez grupos sociales que también fueron puestos en correspondencia, pero que no serán analizados en el presente trabajo. Tales grupo son los siguientes: "clase media", "obreros", "cartoneros", "piqueteros", "empresarios", "beneficiarios de planes sociales", "desocupados", "estudiantes universitarios", "iglesia" y "partidos políticos". 


\begin{tabular}{|c|c|c|c|c|c|}
\hline & \multicolumn{5}{|c|}{ Cuadro $n^{\circ} 1$} \\
\hline & \multicolumn{5}{|c|}{$\begin{array}{c}\text { Grados de proximidad a los "Delegados de la Comisión Interna" } \\
\text { según "Autodefinición política" (en porcentajes) }\end{array}$} \\
\hline \multirow{2}{*}{$\begin{array}{l}\text { Grados de } \\
\text { proximidad }\end{array}$} & \multicolumn{5}{|c|}{ Autodefinición política } \\
\hline & $\begin{array}{c}\text { Izq / } \\
\text { Ctro.izq }\end{array}$ & Centro & $\begin{array}{l}\text { Derecha } \\
\text { / Ctro. } \\
\text { Derecha }\end{array}$ & $\begin{array}{c}\text { NINGUN } \\
\text { A }\end{array}$ & Total \\
\hline $\begin{array}{l}\text { Cerca / } \\
\text { Muy cerca }\end{array}$ & 64 & 35 & 21 & 32 & 38 \\
\hline $\begin{array}{l}\text { Ni cerca ni } \\
\text { lejos }\end{array}$ & 14 & 15 & 14 & 18 & 15 \\
\hline $\begin{array}{l}\text { Lejos / } \\
\text { Muy lejos }\end{array}$ & 22 & 50 & 65 & 50 & 47 \\
\hline Total & 100 & 100 & 100 & 100 & 100 \\
\hline
\end{tabular}

$x^{2}: 25$; g de 1. 6; Prob: 0,000. Fuente: base de datos propia.

Este cuadro nos indica que existe una muy alta correlación entre las variables "Autodefinición política" y "Grado de proximidad" a los "Delegados de la Comisión Interna" $"$. Quienes expresan el mayor grado de proximidad a los delegados de la comisión interna son aquellos trabajadores pertenecientes a una cultura política de izquierda, mientras que el máximo valor opuesto, quienes más lejos se sienten de dichos delegados, son los que se definen de derecha. Más aún, podemos apreciar que existe prácticamente una similitud matemática invertida entre ambas culturas con respecto al grado de proximidad a los delegados de la Comisión Interna que resulta sorprendente.

Por otra parte, observamos un comportamiento análogo entre aquellos que se definen de "Centro" y quienes optan por no encuadrarse en opción política alguna, a quienes reunimos en la categoría "Ninguna". Aunque más atenuado que entre los trabajadores que se definen de derecha, es claro que el comportamiento de aquellos se aproxima mucho más a estos últimos que a los que se definen de izquierda: el grado de lejanía respecto de los delegados de la comisión interna alcanza el 50\% en ambas poblaciones ("Centro" y "Ninguna").

Cuando pasamos al análisis del grado de proximidad expresado por los encuestados con respecto a los dirigentes de FOETRA, manteniendo como variable independiente "Autodefinición política", observamos una clara polarización que tiende

${ }^{16}$ A los fines de volver claramente observable este fenómeno, suprimimos los pocos casos encuadrados en la categoría NS/NC. 
a dividir al universo en dos grandes grupos. Sin embargo, vale la pena remarcar una serie de fenómenos muy sugerentes. Al igual que en el cuadro anterior, optamos por no incluir los casos comprendidos en la categoría NS/NC.

\begin{tabular}{|c|c|c|c|c|c|}
\hline & \multicolumn{5}{|c|}{ Cuadro $n^{\circ} 2$} \\
\hline & \multicolumn{5}{|c|}{$\begin{array}{l}\text { Grados de proximidad a los dirigentes de FOETRA según "Auto- } \\
\text { definición política" (en porcentajes) }\end{array}$} \\
\hline \multirow{2}{*}{$\begin{array}{c}\text { Grados de } \\
\text { proximi- } \\
\text { dad }\end{array}$} & & utodefini & ión política & & \\
\hline & $\begin{array}{l}\text { Izq / } \\
\text { Ctro.izq }\end{array}$ & Centro & $\begin{array}{l}\text { Derecha } \\
\text { / Ctro. } \\
\text { Derecha }\end{array}$ & $\begin{array}{l}\text { NINGUN } \\
\text { A }\end{array}$ & Total \\
\hline $\begin{array}{c}\text { Cerca / } \\
\text { Muy cerca }\end{array}$ & 47 & 25 & 21 & 18 & 31 \\
\hline $\begin{array}{l}\text { Ni cerca ni } \\
\text { lejos }\end{array}$ & 16 & 10 & 21 & 20 & 17 \\
\hline $\begin{array}{c}\text { Lejos / } \\
\text { Muy lejos }\end{array}$ & 37 & 65 & 58 & 62 & 52 \\
\hline Total & 100 & 100 & 100 & 100 & 100 \\
\hline
\end{tabular}

$x^{\mathbf{2}}$ : 37,5; g. de 1.: 12; Prob: 0,000. Fuente: base de datos propia.

En primer lugar, es interesante observar un grado de homogeneidad remarcable entre todas aquellas identidades que no se reconocen de izquierda a la hora de expresar su proximidad a los dirigentes de FOETRA: tanto los que se sienten "Cerca/Muy cerca" como aquellos que se ubican "Lejos/Muy Lejos" demuestran un comportamiento similar. Se advierte una leve dispersión entre aquellos que se encuentran reunidos en la categoría "Ni cerca/Ni lejos". En resumen, son bajos los grados de proximidad y bastante alta la percepción de lejanía. Nuevamente, la fuerte asociación de las variables, reflejadas en el coeficiente que expresa el chi cuadrado, nos indica la fuerte influencia de la dimensión "cultura política" para comprender qué involucra la percepción de proximidad que tienen los trabajadores sobre diferentes estamentos sindicales.

Entre aquellos que se definen de izquierda el valor más elevado se encuentra en la categoría "Cerca/Muy cerca" con el $47 \%$ del total de este grupo, precisamente el comportamiento contrario que se verifica en las restantes identidades políticas. Pero al mismo tiempo vemos cómo de los 17 puntos porcentuales que pierde esta categoría respecto de la variable "Grado de proximidad a los Delegados de la Comisión Interna" tan solo 2 puntos incrementan la categoría "Ni cerca ni lejos" y los 15 puntos restantes pasan a engrosar la categoría "Lejos/Muy lejos". 
Diversas lecturas pueden hacerse para comprender este fenómeno:

A) En primer lugar, observamos que la dimensión referida a la "cultura política" de los trabajadores incide claramente a la hora de expresar grados de proximidad con respecto a sus diferentes ámbitos organizativos. Esto es particularmente palpable con aquellos trabajadores que NO se reconocen de izquierda. No obstante existe un matiz interesante que se verifica en las categorías "Centro" y "Ninguna": ambas demuestran cómo incide el fenómeno que llamamos proximidad real con los trabajadores de la Comisión Interna ya que la percepción de lejanía se incrementa ante los dirigentes de FOETRA en 15 y 12 puntos porcentuales respectivamente. Entre aquellos trabajadores que se identifican con la categoría "Derecha-Centro derecha", la dispersión es menor, incluso desciende 7 puntos porcentuales.

B) El grado de proximidad ante el sindicato divide aguas claramente. Si el factor proximidad real podría estar incidiendo en el grado de proximidad que expresaron los trabajadores que se autoidentifican de izquierda, respecto de los delegados de la "Comisión Interna", éste se debilita cuando aparecen en escena los dirigentes de FOETRA. Aquí se vuelve evidente la incidencia de la dimensión ideológica ${ }^{17}$.

Ahora bien, observemos qué ocurre cuando indagamos en el grado de proximidad a los dirigentes de la Confederación General del Trabajo (CGT):

${ }^{17}$ Llamamos "dimensión ideológica" a la representación del mundo y del orden social que manifiestan los trabajadores en cuestión y que tiene como eje la adscripción a una cierta cultura política. En el presente trabajo intentamos volver observable que la pertenencia a las diferentes culturas políticas, expresadas en las diversas categorías de la variable independiente, pueden ser tomadas como factores explicativos de comportamientos sociales disímiles en el interior de un colectivo laboral que se presume fuertemente homogéneo. 


\begin{tabular}{|c|c|c|c|c|c|}
\hline & \multicolumn{5}{|c|}{ Cuadro $n^{\circ} 3$} \\
\hline & \multicolumn{5}{|c|}{$\begin{array}{l}\text { Grados de proximidad a los dirigentes de la CGT según } \\
\text { "Autodefinición política" (en porcentajes) }\end{array}$} \\
\hline \multirow{2}{*}{$\begin{array}{l}\text { Grados de } \\
\text { proximidad }\end{array}$} & & Autodefin & ión política & & \\
\hline & $\begin{array}{l}\text { Izq / } \\
\text { Ctro.izq }\end{array}$ & Centro & $\begin{array}{l}\text { Derecha } \\
\text { / Ctro. } \\
\text { Derecha }\end{array}$ & NINGUNA & Total \\
\hline $\begin{array}{c}\text { Cerca / } \\
\text { Muy cerca }\end{array}$ & 13 & 5 & & & 31 \\
\hline $\begin{array}{l}\text { Ni cerca ni } \\
\text { lejos }\end{array}$ & 16 & 10 & 36 & 13 & 17 \\
\hline $\begin{array}{c}\text { Lejos / } \\
\text { Muy lejos }\end{array}$ & 71 & 85 & 64 & 87 & 52 \\
\hline Total & 100 & 100 & 100 & 100 & 100 \\
\hline
\end{tabular}

En este cuadro encontramos que el grado de lejanía que expresa el conjunto de los trabajadores telefónicos respecto de los dirigentes de la CGT es bastante homogéneo y por cierto muy elevado. Visto y considerando que continúa existiendo una fuerte correlación de las variables, podríamos reforzar nuestra hipótesis de la influencia cierta que ejerce el factor proximidad real para explicar los grados de lejanía y cercanía, aunque en estrecha relación con el carácter ideológico que se verifica en la pertenencia a una cultura política o a otra. Evidentemente éste es el camino que nos conduciría a conocer las razones por las cuales los dirigentes de la CGT son percibidos como muy distantes por un conjunto tan heterogéneo de trabajadores, aunque ahondar en tales causas no constituye el objeto de este trabajo.

Estos primeros cuadros comienzan a advertirnos que la atribución de una cierta representación propia del nuevo espíritu del capitalismo puede distar sensiblemente de sus configuraciones especulativas. Dicho de otro modo: si bien puede existir un acuerdo extendido respecto a los grandes lineamientos que sigue un cierto modelo de management, cuyos contornos son definidos con claridad por la referida literatura de los años ' 90 , esto no implica que los trabajadores involucrados por tal diseño organizacional reflejen de manera automática las representaciones sociales que se les pretende atribuir.

En tal sentido, el cuadro $\mathrm{n}^{\circ} 4$ presenta una serie de particularidades que es preciso analizar detenidamente: 


\begin{tabular}{|c|c|c|c|c|c|}
\hline & \multicolumn{5}{|c|}{ Cuadro $n^{\circ} 4$} \\
\hline & \multicolumn{5}{|c|}{ "Percepción del sindicato según Autodefinición política" } \\
\hline Percep- & \multicolumn{5}{|c|}{ Autodefinición política } \\
\hline & $\begin{array}{c}\text { Izq / } \\
\text { Ctro.izq }\end{array}$ & Centro & $\begin{array}{l}\text { Derecha } \\
\text { / Ctro. } \\
\text { Derecha }\end{array}$ & $\begin{array}{c}\text { NINGUN } \\
\text { A }\end{array}$ & $\begin{array}{l}\text { To- } \\
\text { tal }\end{array}$ \\
\hline $\begin{array}{c}\text { Una } \\
\text { forma de } \\
\text { conseguir } \\
\text { una obra } \\
\text { social }\end{array}$ & 8 & & & 3 & 5 \\
\hline $\begin{array}{l}\text { Una } \\
\text { fuente de } \\
\text { corrup- } \\
\text { ción }\end{array}$ & 14 & 35 & 36 & 35 & 27 \\
\hline $\begin{array}{l}\text { Nuestra } \\
\text { organiza- } \\
\text { ción } \\
\text { como } \\
\text { trabaja- } \\
\text { dores }\end{array}$ & 76 & 60 & 50 & 60 & 65 \\
\hline NS/NC & 2 & 5 & 14 & 2 & 3 \\
\hline Total & 100 & 100 & 100 & 100 & 100 \\
\hline
\end{tabular}

Observemos en primer lugar que si tomamos como referencia la distribución de valores presente en la columna total y la comparamos con la forma que asume tal distribución en las columnas restantes, parecería que estamos frente a un comportamiento similar, o al menos que expresa una limitada dispersión estadística: en las cuatros categorías que expresan la autodefinición política de los trabajadores encontramos el valor menor en "Una forma de conseguir una obra social" y el valor más elevado en la categoría final de la variable dependiente "Nuestra organización como trabajadores". Sin embargo, esta lectura cambia sustantivamente cuando compara- 
mos la distribución de valores entre la izquierda y el resto de las identidades políticas.

En segundo lugar, este cuadro nos indica que si bien existe asociación entre las variables, la misma no es tan nítida como en el resto de los cuadros analizados hasta el momento. Esto puede ocurrir o bien las categorías construidas para la pregunta "Qué es para ud el sindicato" no son las adecuadas para que exista una asociación entre las variables o bien porque la muestra no es lo suficientemente representativa para que puedan aparecer cristalizadas las diversas identidades sociales en torno a las categorías construidas (la ausencia de valores en dos celdas tiende a reforzar esta hipótesis).

No obstante, es interesante remarcar que sólo el $14 \%$ de los que se definen de izquierda sostienen que el sindicato es una fuente de corrupción, categoría que expresa un homogéneo $35 \%$ de las opiniones en las tres categorías restantes. Cuando dirigimos nuestra mirada a la categoría "Nuestra organización como trabajadores" encontramos reunidos a tres de cada cuatro trabajadores que se reconocen de izquierda. En dicha categoría los valores presentes en las restantes identidades políticas caen 16 puntos porcentuales entre los de "Centro" y "Ninguna" y en 26 puntos entre aquellos que se reconocen de "Derecha". Es decir, que para los trabajadores que se definen de izquierda el sindicato es, de manera dominante, la forma que asume "Nuestra organización como trabajadores". Pero es preciso remarcar que esta categoría también expresa la posición mayoritaria de las identidades restantes, aunque se observa una mayor dispersión de los valores. En tal sentido, apreciamos una singularidad que atrajo nuestra atención: la elevada proporción de entrevistados que, reconociéndose de derecha, optan por encuadrarse en la categoría NS/NC ante la pregunta “¿Qué es para ud. el sindicato?”. Observemos que los 14 puntos porcentuales que allí encontramos septuplican los valores presentes en la misma categoría entre los que se definieron de izquierda y prácticamente quintuplican los valores de la columna que expresa los totales. ¿A qué se debe este extraño comportamiento?

Veamos el cuadro que sigue a continuación: 


\begin{tabular}{|c|c|c|c|c|c|}
\hline & \multicolumn{5}{|c|}{ Cuadro $n^{\circ} 5$} \\
\hline \multicolumn{6}{|c|}{$\begin{array}{c}\text { Importancia atribuida al sindicato según "Autodefinición política" } \\
\text { (en porcentajes) }\end{array}$} \\
\hline \multirow{2}{*}{$\begin{array}{l}\text { Importancia } \\
\text { atribuida al } \\
\text { sindicato }\end{array}$} & & Autodefi & ición polít & & \\
\hline & $\begin{array}{l}\text { Izq / } \\
\text { Ctro.izq }\end{array}$ & Centro & $\begin{array}{c}\text { Derecha } \\
\text { / Ctro. } \\
\text { Derecha }\end{array}$ & NINGUNA & Total \\
\hline $\begin{array}{l}\text { Muy im- } \\
\text { portante }\end{array}$ & 56 & 32 & 14 & 23 & 35 \\
\hline Importante & 30 & 42 & 43 & 46 & 40 \\
\hline $\begin{array}{c}\text { Poco o } \\
\text { nada Im- } \\
\text { portante }\end{array}$ & 14 & 26 & 43 & 31 & 25 \\
\hline Total & 100 & 100 & 100 & 100 & 100 \\
\hline
\end{tabular}

$x^{2}$ : 18,37; g. de 1: 6; Prob: 0,005. Fuente: base de datos propia.

En principio podríamos afirmar que existe una fuerte correlación entre las variables "Grado de importancia atribuida al sindicato" y "Autodefinición política". Mientras que la mayoría de los trabajadores que se definen como perteneciendo a una cultura política de izquierda consideran que el sindicato es muy importante (56\%), esta cifra se reduce a un escaso $14 \%$ entre aquellos que consideran al sindicato carente de toda importancia. Por el contrario, en el caso de los trabajadores que se reconocen en una cultura política de derecha, la distribución de valores es exactamente inversa: sólo un $14 \%$ declara que el sindicato es muy importante mientras que aquellos que consideran que es poco o nada importante logran una adhesión del $43 \%$.

Por otra parte, las categorías "Centro" y "Ninguna" asumen un comportamiento similar entre sí con escasa dispersión estadística cuando observamos la distribución de valores en las tres categorías que expresan a la variable dependiente. Pero más interesante aun es observar con detenimiento que la importancia atribuida al sindicato es, por cierto, bastante elevada en aquellas culturas políticas que no pertenecen al campo de la izquierda. En efecto, para las categorías "Centro", "Derecha/Ctro. Derecha" y "Ninguna" un 74\%, 57\% y 69\% de los entrevistados expresa que el Sindicato es "Importante/Muy Importante", respectivamente. Por lo tanto si uno de los rasgos que caracterizaba al nuevo espíritu del capitalismo refería a la creciente individualización de los vínculos humanos, tal cual hemos podido corroborar, algo 
pasó a lo largo de estos últimos veinte años para que las identidades resultantes del proceso privatizador no reflejasen el individualismo proclamado como su sello distintivo. Un dato ilustrativo de este fenómeno puede verificarse en que aquellas culturas políticas claramente refractarias de la tradición ligada a la izquierda, le otorgan un grado de importancia al sindicato difícilmente esperable al momento de producida la privatización de la empresa pública.

\section{El enigma de la categoría "Ninguna"}

Antes de avanzar en el análisis de los cuadros que siguen a continuación, es necesario advertir que no pretendemos bucear en las formas y contenidos que asume la identidad "peronista" para el conjunto de los trabajadores. Numerosas investigaciones y prestigiosos ensayos abordan este complejo fenómeno social argentino que es el Peronismo, cuya especificidad excede con holgura los límites del presente trabajo ${ }^{18}$.

Recordemos el gráfico №5. Allí veíamos que las categorías "Izquierda" y "Centro Izquierda", que luego reuniríamos en una sola categoría para referirnos volver observable con mayor nitidez la cultura política de izquierda, alcanzaban un nada despreciable $39,2 \%$ del total de los entrevistados. Cuando dirigíamos nuestra mirada hacia las categorías "Centro", "Centro-derecha" y "Derecha" observábamos que, agrupadas, estas identidades reunían sólo el 15,7\%. Sin embargo, si dirigíamos nuestra mirada a las categorías "Ninguna" y "NS/NC" tenemos allí reunido nada menos que el $45,3 \%$ de los valores totales de nuestra base de datos. Pensémoslo en términos excluyentes: el $39,2 \%$ de nuestra base de define de izquierda mientras que el $60,8 \%$ restante NO lo es. En tal sentido, el análisis que realizáramos de los cuadros expuestos hasta aquí nos permite sostener la sugerente capacidad explicativa que tiene la dimensión "cultura política": es un hecho la asociación existente entre la variable independiente "autodefinición política" y todas aquellas con las que ha sido puesta en correlación.

Podría pensarse, con absoluta legitimidad, que nuestro intento por escrutar la "autodefinición política" de los trabajadores telefónicos por medio de las definiciones más tradicionales (izquierda-derecha) es demasiado laxa, visto y considerando que son numerosos los trabajadores que se mantienen al margen de toda definición. Sin embargo, hemos podido demostrar que el comportamiento de los que optan por las categorías "Ninguna" (la categoría "NS/NC" fue desechada para evitar que los pocos casos que aquí se concentraran incidieran sobre el coeficiente de correlación

${ }^{18}$ Nos permitimos sugerirle al lector ávido por conocer este extraordinario y complejo fenómeno social las obras que siguen a continuación, cuyas referencias bibliográficas podrá encontrar al final del presente trabajo: Portantiero, J.C. y Murmis, M (1984); Horowicz, A. (1991); Borón et al (1995); Torre, J.C. (2006); James, D. (1999). 
chi cuadrado de Pearson) se comportan de manera similar a los que se definen de "Centro" y "Centro-derecha". Es decir, estas categorías, las que tienen en común NO ser de izquierda, se comportan de forma bastante homogénea, con algunas dispersiones de orden menor.

Pero siguiendo con nuestro razonamiento previo, veamos qué ocurre cuando indagamos en tres identidades que atraviesan la construcción de la ciudadanía en la Argentina desde la posguerra hasta el presente. Aquí no hay posibilidad de refugiarse en laxitud alguna:

\begin{tabular}{|c|c|c|c|c|c|}
\hline & \multicolumn{5}{|c|}{ Cuadro $n^{\circ} 6$} \\
\hline & \multicolumn{5}{|c|}{$\begin{array}{l}\text { Relación con el Peronismo según "Autodefinición política" } \\
\text { (en porcentajes) }\end{array}$} \\
\hline \multirow{2}{*}{$\begin{array}{l}\text { Relación con } \\
\text { el Peronismo }\end{array}$} & \multicolumn{5}{|c|}{ Autodefinición política } \\
\hline & $\begin{array}{l}\text { Izq / } \\
\text { Ctro.izq }\end{array}$ & Centro & $\begin{array}{l}\text { Derecha } \\
\text { / Ctro. } \\
\text { Derecha }\end{array}$ & NINGUNA & Total \\
\hline Peronista & 42 & 30 & 29 & 19 & 35 \\
\hline No Peronista & 48 & 40 & 50 & 32 & 40 \\
\hline Antiperonista & 8 & 5 & 7 & 2 & 25 \\
\hline NS/NC & 2 & 25 & 14 & 47 & \\
\hline Total & 100 & 100 & 100 & 100 & 100 \\
\hline
\end{tabular}

La identidad peronista atraviesa a todas las identidades políticas. Es cierto que entre aquellos que se definen de "izquierda" encontramos el valor más alto para todos los encuestados que se definen como peronistas (42\%). Observemos también que entre aquellos que se definen como "No peronistas" la distribución de valores es fuertemente homogénea entre izquierda y derecha, oscilando de un $48 \%$ a un $50 \%$ respectivamente. Caso similar para el fenómeno del Antiperonismo, que hoy en día vuelve a estar en boga en la Argentina, aunque remozado en su inherente complejidad.

No obstante, el caso más curioso lo presenta la celda que reúne al $47 \%$ que habiendo respondido "Ninguna" en "Audefinición política" tampoco se pronuncian con respecto a las tres categorías señaladas ("Peronista", "No peronista" y "Antiperonista" respectivamente). Al igual que en el caso anterior, la categoría NS/NC no formaba parte de las categorías ofrecidas como alternativas de respuestas posibles. 
Esta identidad "Ninguna-NS/NC" nos llama particularmente la atención. Si tomamos en cuenta que este grupo reúne 43 entrevistados, apreciaremos que nos encontramos frente al $19,54 \%$ de nuestra base de datos. Se trata, entonces, de una porción importante de nuestro relevamiento.

En primer lugar nos interesó conocer la edad de este grupo. Descubrimos que el $50 \%$ de ellos no supera los 31 años y si estableciéramos, arbitrariamente, un corte en los 40 años observaremos que allí se concentra el 80,9\% del universo. Sin dudas, nos encontramos ante una población joven.

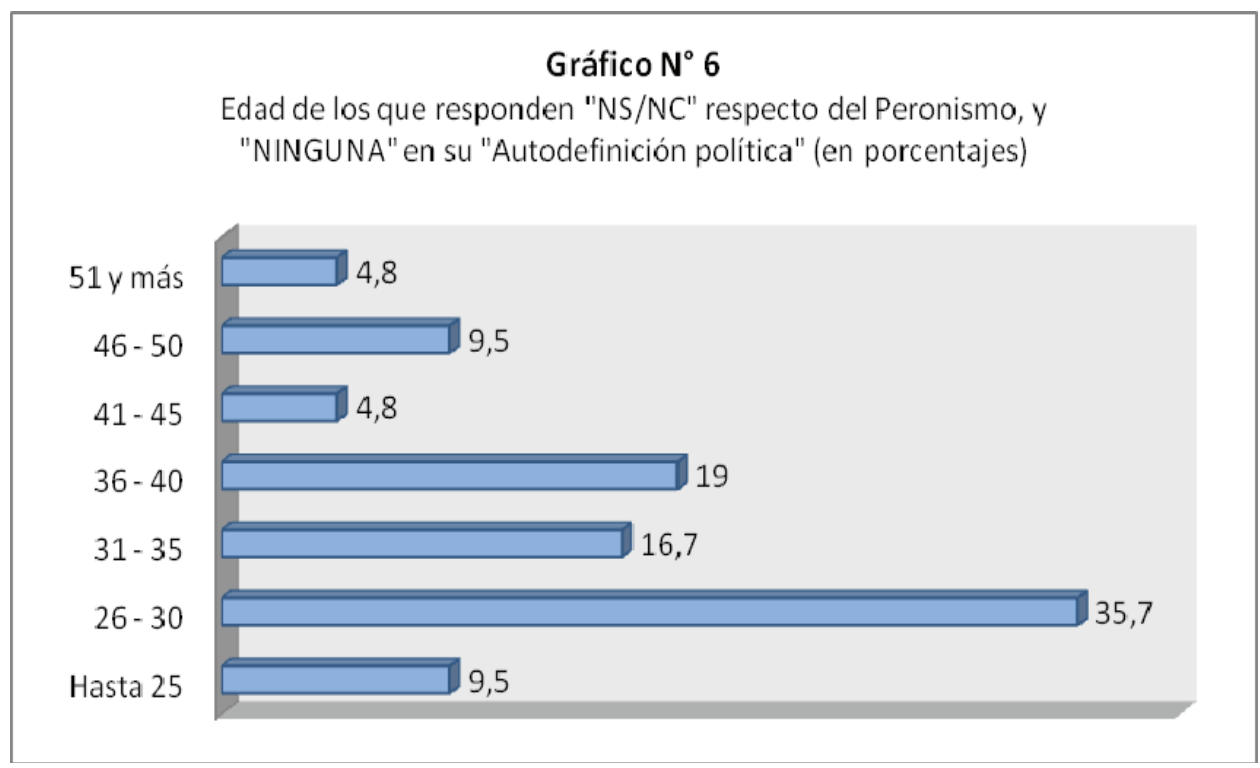

Esto nos hizo enfrentar una pregunta inmediata. ¿Qué posible relación se ocultará entre esta ausencia de toma de posición y la juventud de esta población? En tal sentido, es preciso que acudamos a la importante acumulación de conocimiento que logramos a lo largo de estos últimos diez años y que nos permitió conocer el carácter y el contenido que asumió la imposición de una nueva cultura empresarial desde el momento mismo de la privatización de ENTel.

Como remarcáramos más arriba, el elevado promedio de edad en ENTel constituía un problema para las empresas privatizadas. Para el Departamento de RR.HH. de TDA, la obsolescencia técnica de la empresa estatal se trasladaba mecánicamente a sus agentes, los que, por si fuera poco, encarnaban los mayores obstáculos para lograr un incremento exponencial de la productividad laboral que perseguía como objetivo central el nuevo modelo managerial en ciernes. Y por si faltara algún dato complementario, no había identidad laboral presente en la empresa que no estuviera amparada en algún sindicato. 
A poco menos de diez años de transcurrida la privatización de ENTel, un mando medio-alto del Departamento de RR.HH. nos decía lo siguiente:

"Se busca, fundamentalmente, gente flexible. Flexible a los cambios, abierta al aprendizaje y al auto-aprendizaje. Es decir, el mensaje es el siguiente: el gerente de desarrollo individual es usted mismo. La empresa brinda toda una serie de herramientas, de mecanismos, de cursos de formación. Se invierte mucho en formación, pero el motor de cambio y de actualización debe ser usted mismo. Se busca este tipo de empleado. Pero también buscamos una orientación hacia los resultados. Empleados orientados a resultados. Orientados a la calidad, pero si la calidad supone que hay que esperar tres años para alcanzarla, no va. La prioridad es el resultado. Es decir, se busca la pro-actividad, un perfil de empleado pro-activo, resolutivo. Pero también una cuestión de trabajo en equipo. Se privilegia mucho el tipo de empleado que obtiene resultados. Pero es necesario que obtenga tales resultados en una buena relación con el grupo en el cual se encuentra. Si hablamos de un nivel de conducción, queremos que esta persona pueda obtener resultados pero en un buen clima de trabajo, si es posible. Nosotros cuestionamos mucho el tipo de liderazgo autocrático, autoritario. Esto no quiere decir que no haya algunos casos, pero saben bien que están en la mira. $\mathrm{O}$, al menos, saben que eso no está bien. Lo que se pretende es un tipo de líder más participativo. No paternalista, del tipo de decir 'mis empleados son lo más importante y si puedo cumplir los resultados y los objetivos que fija la empresa tanto mejor'. No, no queremos eso. Hay que alcanzar los objetivos, tener resultados pero cuidando la relación con el grupo. En definitiva, se busca un tipo de cultura integradora. La cultura integradora habla de la consecución de los objetivos pero a través de un buen ambiente de trabajo. Esta es la cultura que deseamos". (Pierbattisti, 2008: 123-124).

Resulta evidente que la cultura individualista que caracteriza al nuevo modelo managerial de los ' 90 , cuya literatura desmenuzan con rigor Boltanski y Chiapello, se verifica con singular nitidez para el caso de la privatización abordada.

En tal sentido, recordemos la convergencia de las dos tácticas aplicadas por TDA para lograr el deseado "recambio cultural": reducir la plantilla de trabajadores por medio de los Retiros voluntarios y provocar una brusca caída del promedio de edad de aquellos a través de los programas de Jóvenes Profesionales, Técnicos y Administrativos (o Comerciales). El gráfico $\mathrm{n}^{\circ} 7$ es elocuente al respecto: 


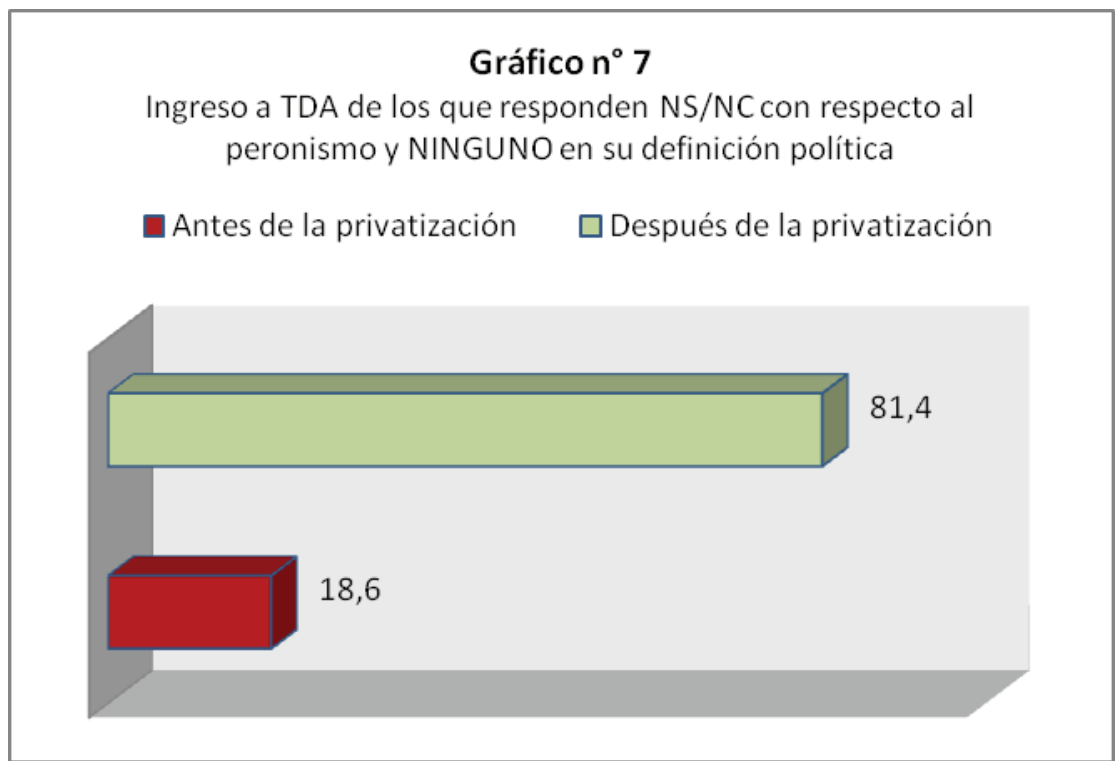

En consecuencia es evidente que estos jóvenes, que no se autodefinen políticamente pero que se comportan como formando parte de una cultura política de derecha, y que ingresaron luego de la privatización de la empresa, estarían expresando un fuerte rechazo por la política pero desde una cultura política claramente definida. Este sugerente sesgo identitario, que por supuesto es preciso profundizar en futuros trabajos, nos conduce a matizar un relativo fracaso del modelo de management que se impuso con la privatización; a pesar de la fuerte crisis que atravesara la empresa en diciembre de 2001 y la valoración positiva que asume el sindicato (tal cual vimos en el cuadro $\mathrm{n}^{\circ} 5$, particularmente). Las variables que pusimos en correlación a lo largo del presente trabajo, y que según el chi cuadrado mostraron una fuerte asociación, nos demostraron que de los "cruces" realizados la categoría ninguna se comportaba de manera similar a las identidades políticas de derecha. Pero al mismo tiempo es importante mantenerse a resguardo de realizar definiciones concluyentes, ya que dicha valoración positiva de la organización sindical estaría poniendo en duda la asociación automática con la proclamada "cultura individualista" propia del nuevo management. Es cierto que aquella puede aparecer reflejada en esta evidente negación de cualquier forma de autodefinición política, pero no es menos cierto que la importancia que se le atribuye al sindicato tampoco se corresponde con el modelo subjetivo que prescribe la literatura managerial de los ' 90 .

En pocas palabras, los matices tienen que ser incorporados a nuestro análisis para evitar caer en los lugares comunes, regidos por los blancos o negros. Si bien es cierto que en principio existe una fuerte correlación entre cierta identidad joven, ingresante a TDA luego de la privatización, que se define como NO perteneciente a 
cultura política alguna, y que sin embargo manifiesta un comportamiento similar a aquellos que se definen de derecha, también es del orden de lo objetivo que las instancias colectivas que concentran la representación de los trabajadores lejos están de ser despreciadas (como cabría esperar ajustándose a los objetivos que perseguía el modelo organizacional impuesto hace veinte años).

\section{Reflexiones finales}

Transcurridos ya veinte años de la privatización, la resultante de ese complejo proceso social sigue arrojando nuevas sugerencias para pensar el despliegue del "nuevo espíritu del capitalismo", que Boltanski y Chipello describieran con singular agudeza.

En primer lugar, toda privatización ofrece un escenario estratégico difícil de encontrar en otros procesos sociales porque allí se pone de manifiesto un tránsito definitivo: el que signa el paso de una cultura estatal a otra atravesada por el funcionamiento pleno de la ley del valor (Marx, 2002).

Sin dudas las reformas del Estado que marcaron a fuego el paso de los últimos treinta años en Occidente, y que coincide con el período que abordan Boltanski y Chiapello para analizar en qué consiste el nuevo espíritu del capitalismo, fueron incorporando nuevas territorialidades sociales al desarrollo pleno de la ley del valor. Desde nuestra perspectiva, este es el fenómeno que explican las mutaciones epistemológicas verificadas en las investigaciones que lleváramos a cabo, cuyo núcleo estructurante refiere a la irrupción del concepto de empleabilidad.

Es en este punto donde tomamos distancia de la investigación llevada a cabo por los académicos franceses y por los singulares recortes que producen las tres escuelas que nutrieron nuestro marco teórico. Para nosotros la empleabilidad no sólo remite a un conjunto de habilidades, competencias y saberes a las que está compelido cada trabajador para administrar, como si se tratase efectivamente de un empresario de sí mismo, su "capital humano". La empleabilidad designa el valor de cambio de la mercancía fuerza de trabajo en un contexto en el cual las relaciones sociales asumen cada vez más relaciones donde se intercambia valor (Marx, 2007).

Así, la empleabilidad es la resultante de un complejo proceso de individualización de la fuerza de trabajo en donde la codificación de los comportamientos humanos en función de una grilla de inteligibilidad económica ocupará un lugar central. Esta es una de las características más distintivas de la doctrina económica neoliberal, inescindible de la ofensiva capitalista que permitió, canalizó y le otorgó sentido y legitimidad a los procesos de Reforma del Estado que volvieron posibles la existencia de lo que hoy conocemos como empleabilidad.

Dicho de manera más simple aún, los complejos modelos manageriales que se fueron imponiendo como correlato fáctico del nuevo espíritu del capitalismo tiene como objetivo estratégico producir una escisión entre la mercancía fuerza de trabajo y el cuerpo que la soporta. A esto refiere, en última instancia, el concepto de empleabilidad, el modelo de las competencias, la teoría del capital humano y la multi- 
plicidad de mecanismos existentes para verificar, en términos individuales, cuán productivo es un cuerpo.

Es en este punto donde observamos el principal déficit del tratado escrito por Boltanski y Chiapello, que involuntariamente se prolonga en las tres Escuelas a las que aludiéramos oportunamente: mientras que sus perspectivas tienen un enorme poder descriptivo no pueden interpretar, adecuadamente, el carácter real que asume la expansión de la formación social capitalista a escala planetaria y la centralidad de la valorización del capital como sujeto de dicha expansión. En tal sentido no desconocemos que nuestro objeto de estudio estuvo enfocado en empresas transnacionales, donde con particular nitidez se observa el carácter cada vez más homogéneo que tiene la aplicación de modelos de management en diversos países. La imposición en Francia del mismo modelo managerial que France Télécom aplicara en la Argentina hace exactos veinte años da cuenta de ello.

Sin embargo acordamos con Boltanski y Chiapello en que, más allá de la forma en que se designe, existe algo que bien podría llamarse "nuevo espíritu del capitalismo"; designación que refiere a un proceso en curso cuya direccionalidad, así como las reacciones que suscita, nos reserva un apasionante final abierto y bien alejado de todo presupuesto especulativo.

Tomemos el caso de la Argentina, y particularmente el que refiere a nuestra problemática. Para numerosos investigadores en el campo de las ciencias sociales y económicas (Anderson, 2003; Negri, 2002; Petras, 2000; Salama, 2002), este país constituyó un singular objeto de estudio puesto que no existió mayor laboratorio de experimentación del neoliberalismo en el mundo. La crisis de diciembre de 2001, con su cortejo de represión, muertos y heridos, anticipaba las inevitables consecuencias que pueden conducir al despliegue irrestricto del nuevo espíritu del capitalismo reseñado.

Dicha crisis impactó de lleno sobre los contenidos del modelo managerial impuesto con las privatizaciones. Particularmente una vez verificados los estrepitosos resultados de las múltiples iniciativas comerciales que emprendieran los ex-ENTel con los montos recibidos en concepto de Retiro Voluntario.

En suma, tras la crisis de fines de 2001, los pretendidos "colaboradores" y "clientes internos" en ciernes priorizaron sus puestos de trabajo y no dudaron en acudir al sindicato para buscar el asesoramiento y el resguardo que les permita preservar sus empleos. Consideramos que éste es un factor decisivo y fundamental para comprender que aun en aquellas identidades alejadas de una cultura política de izquierda exista un porcentaje tan elevado que considere que el sindicatos es "Importante" y "Muy Importante" (cuadro $\mathrm{n}^{\circ}$ 5); y sobre todo "Nuestra organización como trabajadores" (cuadro ${ }^{\circ} 4$ ).

Concluyendo, podríamos afirmar que en este trabajo procuramos demostrar que la dimensión de la cultura política de los trabajadores es una dimensión que es preciso tener en cuenta para conocer, con rigor, la fuerte impronta, por momentos decisiva, que se les atribuye a los nuevos modelos de gestión de la fuerza de trabajo. Esta es una exigencia imprescindible que incluso nos permite matizar aquellos resultados preliminares que estarían señalando "éxitos" o "fracasos" rotundos. De 
allí para nosotros la utilidad de haber construido una base de datos y conocer las identidades resultantes a veinte años de producida la privatización y a casi diez exactos de la crisis más grave que atravesó la historia reciente de la Argentina.

Es importante remarcar este último aspecto porque si bien coincidimos en que el desenvolvimiento de la formación social capitalista a escala planetaria está siendo acompañado por una codificación de los comportamientos humanos que se subordina, de manera creciente, a una grilla de inteligibilidad económica, no es verdad que de tal dispositivo se deriven mecánicamente las representaciones sociales que les atribuyen los investigadores franceses mencionados; particularmente las que aluden a los modelos de management en pugna.

Es por tal motivo que para conocer las representaciones sociales que impondría el nuevo espíritu del capitalismo, cuyos avatares involucra de modo creciente al conjunto de la especie humana, es preciso valerse del instrumental que nos brindan las ciencias sociales. Suele ocurrir que la delgada línea que separa al conocimiento científico de la literatura erudita puede volverse tan opaca como cautivante.

\section{Referencias bibliográficas}

Alvesson, M.; WIllmott, H. (1992). Critical Management Studies. Londres: SAGE.

Anderson, P. (2003). Neoliberalismo: un balance provisorio. En libro: La trama del neoliberalismo. Mercado, crisis y exclusión social. Emir Sader (comp.) y Pablo Gentili (comps.). Buenos Aires: CLACSO

Disponible en: http://bibliotecavirtual.clacso.org.ar/ar/libros/trama/anderson.rtf

Aruguete, N.; Duarte, M. (2005). Las estrategias sindicales de los trabajadores telefónicos: las distintas lógicas de la acción colectiva. En VII Congreso Nacional de Estudios del Trabajo. Buenos Aires: ASET.

Azpiazu, D.; Schorr, M. (2001). Privatizaciones, rentas de privilegio, subordinacion estatal y acumulación del capital en la Argentina contemporánea. Buenos Aires: Instituto de Estudios y Formación de la CTA.

Basualdo, E. (2006). Estudios de historia económica argentina. Buenos Aires, Siglo XXI.

Baudelot, C. et Establet, R. (2006). Suicide, l'envers de notre monde. Paris, Seuil.

Beccaria, L.; López, N. (1997). Sin Trabajo. Las características del desempleo y sus efectos sobre la sociedad argentina. Buenos Aires: UNICEF/Losada. (Comp).

Becker, G.: Human Capital. A Theoretical and Empirical Análisis, with Special Reference To Education. The University og Chicago Press. Chicago and London. 3rd. Edition. Chicago, 1994. 
Bernoux, P. (1990). La sociologie des organisations. Paris, Seuil.

Bobbio, N. (1998). Derecha e izquierda. Madrid: Taurus.

Boltanski, L et Chiapello, E. (1999). Le nouvel esprit du capitalisme. Paris, Essais Gallimard.

Boron, A.; Mora y Araujo, M.; Nun, J.; Portantieron, J. C.; Sidicaro, R. (1995). Peronismo y menemismo: avatares del populismo en Argentina. Buenos Aires: El cielo por asalto.

Burgi, N. (2007). De la précarité de l'emploi à la négation du vivant. Interrogations? Revue pluridisciplinaire en sciences de l'homme et de la société. $\mathrm{N}^{\circ} 4$. Formes et figures de la précarité. http://www.revueinterrogations.org/BURGI, N. (2006) : La machine à exclure : Les fauxsemblants du retour à l'emploi, Paris, La Découverte.

Decèze, D. (2008). La machine à broyer. De France Télécom à Orange: quand les privatisations tuent. Paris, J.C. Gawsewitch.

Dejours, C. (2009). Travail vivant. 1 : Sexualité et travail. Paris, Payot.

Dejours, C. (2009). Travail vivant. 2 : Travail et émancipation. Paris, Payot.

Dejours, C. (2007). Conjurer la violence. Paris, Payot.

Du Roy, I. (2009). Orange stressé. Le management par le stress à France Télécom. Paris, La Découverte.

Dubar, C.: (1991). La Socialisation. Construction des identités sociales et professionnelles. París: Armand Colin.

Dubar, C.: (2000). La crise des identités. L'interprétation d'une mutation. París: Presses Universitaires de France.

Durkheim, É. (1960). Le suicide. Une étude sociologique. Paris, PUF.

Elias, N.: (1989). El proceso de la civilización. México: F.C.E..

Foucault, M. (2004). Naissance de la biopolitique. París: Gallimard-Seuil.

Foucault, M. (1982). Le sujet et le pouvoir. En Dits et écrits II. Paris: QuartoGallimard (2001). 
Foucault, M. (1975). Surveiller et Punir. Paris: Gallimard.

Garretón, M.A. (1991). "Política cultura y sociedad en la transición democrática". En Nueva Sociedad. N 114 (Julio-Agosto). PP. 43-49.

Goffman, E. (1973). La mise en scène de la vie quotidienne. La présentation de soi. París: Ed. de Minuit.

Horowicz, A. (1991). Los cuatro peronismos. Buenos Aires: Planeta.

James, D. (1999). Resistencia e integración. El peronismo y la clase trabajadora argentina 1946-1976. Buenos Aires: Sudamericana.

Marx, K. (2002). El capital. Buenos Aires, Siglo XXI.

Negri, A. (2002). Diálogo sobre la Globalización, la Multitud y la experiencia Argentina. Buenos Aires: Paidós.

Petras, J. (2000). (2000). La izquierda contraataca, conflicto de clases en América Latina en la era del Neoliberalismo. Madrid: Akal.

Pierbattisti, D. (2011). "Las privatizaciones en la Argentina y Canadá: neoliberalismo, gobierno y reforma del Estado". Revista de la Asociación Argentina de Estudios Canadienses $\mathrm{N}^{\circ} 4$ abril de 2011. Buenos Aires: Editorial La Ley. ISSN: 1851-4448. Págs. 125-147.

Pierbattisti, D. (2010a). "Del trabajador al colaborador: del uso de la teoría del Capital Humano en el proceso de privatizaciones en Argentina (1990-2001)". Revista electrónica Observatorio de la Economía y la Sociedad Latinoamerica$n a . \mathrm{N}^{\circ} 128$. Universidad de Málaga. ISSN: 1696-8352. Disponible en: http://www.eumed.net/cursecon/ecolat/ar/2010/dp.htm

Pierbattisti, D. (2010b). "Marx, Foucault y la Biopolítica: la población como efecto de la ley de acumulación capitalista". En Biopolíticas del Sur. Isabel Cassigoli y Mario Sobarzo, Coord. Págs 123-1444. Santiago de Chile: Ed. De la Universidad de Artes y Ciencias Sociales, ARCIS.

Pierbattisti, D. (2008). La privatización de los cuerpos. La construcción de la proactividad neoliberal en el ámbito de las telecomunicaciones, 1991-2001. Buenos Aires, Prometeo.

Pierbattisti, D. (2005). Destruction et reconstruction des identités au travail en Argentine: la privatisation d'ENTel 1990-2002. Atelier National de Reproduction des Thèses, Lille. 
Pierbattisti, D. (1998). Les nouvelles formes de gestion de la force de travail et mutations des identités professionnelles en Argentine (1991-1995). Tesis de Diplôme d'Etudes Approfondies. Université de Paris I (Panthéon-Sorbonne). Director: Dr. Bruno Lautier. Inédito.

Portantiero, J.C.; Murmis, M. (1984). Estudios sobre los origenes del peronismo. Buenos Aires: Siglo XXI.

Rebon, J. (2007). La empresa de la autonomía. Trabajadores recuperando la producción. Buenos Aires: Ediciones PICASO-Colectivo Ediciones. Colección Ciencias Sociales.

Sainsaulieu, R. (1991). L'identité au travail. París: Presses de la Fondation Nationale des Sciences Politiques.

Salama, P. (2002). Argentine, chronique d'une crise annoncée. En Recherche et Régulation. Grenoble. Disponible en : http://webu2.upmf-grenoble.fr/regulation/

Schultz, T. Human Capital". The Role of Education and of Research. The Free Press, New York - Collier Mac Millian Limited, London. New York, 1971.

Telefonica de Argentina (1991). "Relaciones Interpersonales". Dirección de Recursos Humanos-Servicio de Formación. Buenos Aires: TDA.

- (1997). Creatividad y cambio organizacional. Manual del Participante. MG009. Dirección de Recursos Humanos y Organización. Subdirección de Planificación, Organización y Desarrollo. Gerencia de Capacitación de Telefónica de Argentina. Buenos Aires: TDA.

- (2001). Satisfacción y retención del cliente. Manual del Participante MS016. Dirección de Recursos Humanos y Organización. Subdirección de Planificación, Organización y Desarrollo. Gerencia de Capacitación. Buenos Aires: TDA.

Thuderoz, C. (2006). Histoire et sociologie du management. Doctrines, textes, études de cas. Laussane, Presses Polytechniques et Universitaires Romandes.

Torre, J.C. (2006). El gigante invertebrado. Buenos Aires: Siglo XXI.

Von Mises, L. (1968). La acción humana: Tratado de economía política. Madrid: Sopec.

Zarifian, P. (2001). Le modèle de la compétence. Hauts-de-Seine, Rueil-Malmaison. 